\title{
Simulating the water content and temperature changes in an experimental embankment using meteorological data
}

\author{
Y.J. Cui ${ }^{1,2}$, Y.B. Gao ${ }^{3}$ and V. Ferber ${ }^{4}$ \\ 1: Ecole des Ponts ParisTech, UR Navier-CERMES, France ; cui@ cermes.enpc.fr \\ 2: The China Three Gorges University, Yichang 443002, China \\ 3: Tongji University, Shanghai, China; yanbin-gao@sohu.com \\ 4: Company Charier, vferber@ charier.fr
}

\author{
Corresponding author \\ Prof. Yu-Jun Cui \\ ENPC/CERMES \\ 6 et 8 , av. Blaise Pascal \\ Cité Descartes, Champs-sur-Marne \\ 77455 Marne La Vallée cedex 2 \\ France \\ Tel: 33164153550 \\ Fax : 33164153562 \\ E-mail : cui@ cermes.enpc.fr
}




\begin{abstract}
:
An experimental embankment was constructed in Rouen, France. The construction was completed in December 2004. The first objective of this experiment is to investigate the influence of climatic changes on the soil response such as changes in water content and temperature as well as the induced vertical and horizontal displacements; and the second objective is to investigate the soil response under water flooding from the base of embankment. In this study, the changes in temperature, volumetric water content and suction along the central axis have been analysed using a one-dimensional model and based on the meteorological data obtained in the field. Comparisons made between the measurements and simulations have shown the relevance of the method adopted, provided that suitable boundary conditions and soil parameters are taken into consideration. Moreover, both the simulation and field monitoring showed that climatic effects are limited to a shallow depth, which results from the low permeability of the compacted fill.
\end{abstract}

Keywords: soil-atmosphere interaction; experimental embankment; field measurements; numerical simulation. 


\section{Introduction}

Embankments are made up of unsaturated compacted soils. Their behaviour is strongly affected by the climatic or environmental perturbations. When climatic conditions change, the temperature, water content and suction of soils change. When clayey soils are involved, significant ground movement or soil cracking can occur, leading to possible damage to buildings and geotechnical constructions (Arbizzi et al. 2008, Borde et Despres 2008). Indeed, recent assessment on hazards caused by droughts showed that evapotranspiration is also an important process to be accounted for in natural hazards analysis.

The evapotranspiration process has been widely studied in the field of meteorology and agronomy. Very often, the potential evapotranspiration (PET) is calculated to obtain a first estimate. The most common methods used for PET calculation are the Penman method, the Penman-Monteith method and the Turc method (see Guyot 1997 for a comprehensive review). The actual evapotranspiration (ET) can be determined by either field measurement based on water balance or energy balance, or numerical analysis using standard meteorological data. For the numerical analysis, Choudhury et al. (1986) and Xu and Qiu (1997) developed different models allowing the calculation of ET in the case of bare soils (without vegetation) or homogenous canopy (grass, crops etc.).

For a given soil, when the evapotranspiration is calculated using the models mentioned above, the boundary condition in term of water flux is determined, and further coupled analysis using the finite difference method or finite element method can be performed in order to determine the soil water content variations. This is quite common practice in the field of agronomy. In the field of geological and geotechnical engineering, this approach has been introduced recently but has been met quick development (Wilson et al. 1994, Terlien et al. 1995, Van Beek and Van Asch 1998, Bogaard and Van Asch 2002, Cui et al. 2005, Malet et al. 2005, Zornberg and McCartney 2005, Cui and Zornberg 2008).

The present work presents the monitoring data from an experimental embankment constructed in France, during the first stage of the experiment whose objective was to investigate the influence of climatic changes on the soil thermo-hydro-mechanical responses such as changes in water content and temperature as well as the induced vertical and horizontal displacements. As the main objective of this experiment regards the second stage aiming at investigating the soil response under water flooding from the base of the embankment, the first stage lasted less than one year unfortunately, from early December 2004 to late August 2005. Based on the work of soil-atmosphere modelling of Cui et al. (2005) and Xu and Qiu (1997), the changes in temperature and volumetric water content along the central axis of the embankment have been simulated using meteorological data obtained in the field. The calculation was then compared with the monitoring data in order to verify the adopted approach.

\section{Field monitoring}

The experimental embankment was constructed by roller compaction in Rouen, France, from early August to the end of November 2004. Figure 1 presents a photograph of the embankment near completion. The embankment is $12 \mathrm{~m}$ long, $5.27 \mathrm{~m}$ high, $21 \mathrm{~m}$ large at the base and $5 \mathrm{~m}$ large at the top; it consists of 15 layers 
made of two fill materials. For layers 1 to $5(0-180 \mathrm{~cm}$ from the base) a silty soil, namely A28, was used and for layers 6 to $15(180 \mathrm{~cm}-527 \mathrm{~cm}$ from the base), a silty soil namely SNEC was used. Their physical properties are shown in Table 1 and their grain size distribution curves in Figure 2. Soil A28 has more fine-grained fraction $(<80 \mu \mathrm{m}=97 \%)$ than soil SNEC $(<80 \mu \mathrm{m}=40 \%)$; the clay fraction is also higher in soil A28 $(<2 \mu \mathrm{m}=25 \%)$ than in soil SNEC $(<2 \mu \mathrm{m}=15 \%)$; this explains the larger plasticity index $\left(\mathrm{I}_{\mathrm{p}}\right)$ and the larger methylene blue value $\left(\mathrm{V}_{\mathrm{BS}}\right)$ for soil $\mathrm{A} 28$. Note that $\mathrm{V}_{\mathrm{BS}}$ can be considered as an indirect measure of the specific surface (the specific surface expressed in $\mathrm{m}^{2} / \mathrm{g}$ is about $24 \mathrm{x} \mathrm{V}_{\mathrm{BS}}$ ). According to the French GTR classification (1992), soil A28 belongs to category A1-A2 and soil SNEC belongs to category A1. Both soils belong to lean clay (CL) following the ASTM unified soil classification system.

Soil A28 was designed to be loosely compacted (80\% optimum) whereas soil SNEC was densely compacted (95\% optimum); this design was to emphasise the collapsible behaviour of lower layers made up of A28 soil and the swelling behaviour of upper layers made up of SNEC soil. Figure 3 presents the profile of density determined using both double-gamma probe and gamma densimeter. At each layer, the soil density was measured at various positions. Significant heterogeneity can be observed: the lower layers have a density varying from 1.25 to $1.9 \mathrm{Mg} \mathrm{m}^{-3}$ and the density of the upper layers varies from 1.65 to $2.15 \mathrm{Mg} \mathrm{m}^{-3}$. This is a typical problem when compacting under field conditions. The heterogeneity identified can be related to both material heterogeneity (different clod size distribution) and water content heterogeneity. Actually, any material heterogeneity certainly results in water content heterogeneity because the water content of the clods themselves must be different from the overall water content; this is the case during the equilibration phase (water redistribution due to suction gradient between maro-pores and micro-pores) and this is also the case after the equilibration phase (the water content of clods must be higher because of their smaller pores that generate higher suctions).

Figure 4 presents the instrumentation of the embankment. The numbers of layers are also indicated. A large quantity of sensors were used to monitor the changes in volumetric water content (Time Domain Reflectometry - TDR, 40 points; hyperfrequency loop, which measures the volumetric water content from the measurement of soil permittivity by considering signals having travelled through the hyper frequency loop cable: 10 points), total suction (equitensiometer, 15 points), temperature (thermocouple, 25 points), vertical displacement (device based on Linear Variable Differential Transformer - LVDT, 18 points), and horizontal displacement (string potentiometer, 8 points). All these sensors were installed along four axes: centre, north, south and west at different heights: $0,0.13,0.33,0.53,0.85,1.15,1.81$, $2.075,2.375,2.75,3.21,3.52,3.94,4.66,4.93 \mathrm{~m}$. The centre, south and north axes are on the symmetric plan of the embankment whereas the west axis is under the west slope. Soil water contents were recorded every 12 hours and soil temperatures as well as pore water pressures (suction) were measured every 1 hour. The longer recording time interval for volumetric water content was adopted mainly because of the larger number of sensors (40 TDR and 10 hyperfrequency loop) for a limited recording memory space and of the low variation rate generally observed for volumetric water content under climatic changes (see for instance Cui et al. 2005).

The embankment was also equipped with a meteorological station on the top surface to record the meteorological data every 30 minutes, including solar radiation, precipitation, atmospheric pressure, wind speed at $1.0 \mathrm{~m}$, air temperatures at $0.5 \mathrm{~m}$ 
and $1.0 \mathrm{~m}$, relative humidity at $0.5 \mathrm{~m}$ and $1.0 \mathrm{~m}$ above ground level. The soil surface temperature was also monitored.

In the following, the meteorological data will be presented first. Then the data about soil volumetric water content, soil pore-water pressure (suction) and soil temperature are shown. As the simulations made have involved the central axis, only data recorded along this axis are presented. The displacements measured are quite small over the whole monitoring period: the maximum value of vertical deformation recorded was about $1 \%$ swelling in the near surface zone and the maximum value of horizontal displacements recorded at three levels was less than $0.01 \mathrm{~mm}$. As these measurements are not significant (normal for the low plasticity soils used) and in addition they have been not involved in the calculation, they will not be presented (detailed information about displacement measurements can be found in Vinceslas et al., 2009).

\section{Meteorological data}

Meteorological data were recorded from early December 2004 to late August 2005. They are presented in Figure 5. Maximum daily solar radiation (Figure 5a) increased almost linearly from December to April and then became constant until late August, at about $0.8 \mathrm{~kW} / \mathrm{m}^{2}$. One significant rainfall event was recorded on $4^{\text {th }}$ July $(23.2 \mathrm{~mm} / 30 \mathrm{~min}$, Figure $5 \mathrm{~b})$. The precipitations in December and May were $61 \mathrm{~mm} / \mathrm{month}$ and $51.8 \mathrm{~mm} / \mathrm{month}$ respectively, higher than the average precipitation of $45 \mathrm{~mm} / \mathrm{month}$. The average wind speed was about $1.2 \mathrm{~m} \mathrm{~s}^{-1}$; but several high speeds were recorded, especially on $14^{\text {th }}$ July when it reached $36 \mathrm{~m} \mathrm{~s}^{-1}$ (Figure $5 \mathrm{c}$ ). The relative humidity in air varied between 30 and 100\% (Figure 5d). It seems that there was a seasonal trend in relative humidity changes: the mean value decreased from the beginning of monitoring (December, 2004) to the end of February, 2005; it remained more or less constant afterwards till late August. The air temperatures varied between $-6.7^{\circ} \mathrm{C}$ and $31.6^{\circ} \mathrm{C}$. The minimum value appeared in late February and the maximum in mid June.

Volumetric water content of soil

Figure 6 presents the variations of soil volumetric water content $\theta_{\mathrm{s}}$ over the whole monitoring period along the central axis. Note that in this section the positions of the sensors are indicated by the depths from the top of the embankment. Note also that only measurements from TDR are presented because similar results were recorded by the hyperfrequency sensors. At 34 and $61 \mathrm{~cm}$ depths (Figure 6a): after the first rainfalls from $16^{\text {th }}$ to $26^{\text {th }}$ December 2004, a sharp increase in $\theta_{\mathrm{s}}$ of about $6 \%$ was observed. A stabilisation occurred from $10^{\text {th }}$ January, followed by a new increase probably in response to the rainfalls from $18^{\text {th }}$ to $24^{\text {th }}$ January 2005 . Afterwards, no significant changes were recorded even after the heavy rainfall of $4^{\text {th }}$ July 2005 , suggesting that a balance between infiltration and evaporation was reached. At 114 and $133 \mathrm{~cm}$ depths (Figure 6a), no significant variation of $\theta_{\mathrm{s}}$ occurred till mid April 2005. A gradual increase was observed from mid April to early July 2005, reaching more or less the same value than the upper two levels (about 30\%). At $175 \mathrm{~cm}$ depth (Figures $6 \mathrm{~b}$ ), the measurement shows a significant fluctuation around a value of $27 \%$. This fluctuation is difficult to be explained. At $206 \mathrm{~cm}$ depth, no variation was recorded, with a value around $26.5 \%$. At $289.5 \mathrm{~cm}$ depth, a constant value of about $26.5 \%$ was also recorded. But on the contrary to the measurement at $206 \mathrm{~cm}$ depth, a gradual increase was observed from late March to early May, followed by a stabilisation till the end of the recording period. At $346 \mathrm{~cm}$ depth, the measurement 
showed no significant changes with a value around 32\%. For the deeper levels (Figure 6c), no significant changes occurred for all depths except the depth of $442 \mathrm{~cm}$ where an increase was observed during all the recording period from a starting value relatively low: $20 \%$.

From the observations above, it seems difficult to make a simple correlation between the precipitation and the volumetric water content changes. Different factors could be origin of this difficulty: the significant heterogeneity of density (see Figure 3), the soil nature (two different soils, SNEC and A28) and the sensitivity of the sensors used. Furthermore, the possible non-uniformity of suction after compaction of the embankment would lead internal water redistribution and result in volumetric water content changes. But this phenomenon is believed to take place only in the early recording period.

\section{Soil pore pressure}

Figure 7 shows the pore pressure variations at nine different depths along the central axis. At $61 \mathrm{~cm}$ depth, a sharp increase was recorded on $17^{\text {th }}$ December 2004. This is consistent with the precipitation records. Indeed, no rainfall events were recorded before $16^{\text {th }}$ December and significant rainfalls occurred between $16^{\text {th }}$ and $19^{\text {th }}$ December 2004. A slight gradual increase was then observed, followed by a sharp decrease from early July to early August. Afterwards, a sharp increase occurred till the end of the recording period. This sharp decrease and sharp increase seem difficult to be explained. At $206 \mathrm{~cm}$ depth, no change occurred till $23^{\text {rd }}$ December then a significant increase up to $20 \mathrm{kPa}$ was observed. The value remained more or less constant afterwards. There was probably a technical problem with this sensor considering that the soil seemed to be unsaturated and logically a negative pore pressure should be recorded. At $346 \mathrm{~cm}$ depth, no significant changes were recorded. For the depth of $397 \mathrm{~cm}$, a slight increase occurred but on the whole the measured value was close to that at $346 \mathrm{~cm}$ depth. Note however that the measurements by this sensor by the end of the recording time were also higher than zero; therefore a technical problem can be also suspected. At the depths of 412, 494 and $527 \mathrm{~cm}$, the same variation trend was observed, with a general decrease till late May 2005 followed by an increase. There was also the same variation trend for the depths 442 and $474 \mathrm{~cm}$. But on the contrary to the depths of 412,494 and $527 \mathrm{~cm}$, these two depths showed a constant increase.

Compared to the measurements of volumetric water content, the measurements of pore pressure seem more difficult to be interpreted based on the data of rainfall. This is probably due to the higher sensitivity of suction to the soil density variability and soil nature. Further study is needed to investigate the reliability and sensitivity of the equitensiometers used in the range of suction involved. Note also that many authors have reported that climatic changes seem to affect the surface soil only (Camillo and Gurney 1986, Kondo et al. 1990, Mahfouf and Noilhan 1991, Chanzy and Bruckler 1993). Unfortunately, because no sensors were installed above layer 14 (34 cm depth), it is not possible to know the volumetric water content and pore pressure changes in the near surface zone, even though it is believed to be more significant. This is also one of the motivations for the numerical analysis performed for the near surface zone. 


\section{Soil temperature}

Figure 8 presents the soil temperature measured at different heights above the base of embankment along the central axis. It appears clearly that the lower the soil layer, the less the variation of soil temperature. In addition, all the depths showed a temperature decrease in the cold season and a temperature increase in the hot season; the decrease-increase transition time was function of soil depth: the deeper the soil, the later the temperature transition. This observation suggests that on the central axis considered, the variations were rather one-dimensional.

Figure 9a shows the temperature profiles at different times on $20^{\text {th }}$ June, including the soil surface temperature and the air temperatures at $0.5 \mathrm{~m}$ and $1.0 \mathrm{~m}$ respectively above the embankment surface. It appears clearly that during 24 hours, the temperature changes were limited to $34 \mathrm{~cm}$ depth. This depth limit changed with a longer period. Indeed, if a five-month period is considered, the soil temperature changed at all the depths (Figure 9b).

\section{Soil heat and mass flow models}

The one-dimensional water and heat flow model presented by Wilson et al. (1994) is adopted. Obviously, considering the geometry of the embankment (12 m long, $5.27 \mathrm{~m}$ high, $21 \mathrm{~m}$ large at the base and $5 \mathrm{~m}$ large at the top), a two-dimensional or three-dimensional calculation must be more rational. However as a first attempt, a one-dimensional analysis was made for changes in temperature, volumetric water content and suction along the central axis of the embankment. This is based on two considerations: i) only the central axis was considered and it is believed that along this axis of symmetry an one-dimensional analysis is plausible, and ii) one of the main motivations of this work is to assess the suction changes numerically in the near surface zone where the soil-atmosphere interaction was the strongest but the instrumentation was unfortunately missing; this zone with significant changes in suction and volumetric water content has been found to be thin and it seems that an one-dimensional analysis was enough considering the relatively large surface area. Furthermore, the temperature changes showed in Figure 8 support the approach adopted. In the numerical simulations, the silty soils involved were regarded as non deformable. This assumption is supported by the very small vertical deformation (less than $1 \%$ ) and horizontal displacement (less than $0.01 \mathrm{~mm}$ ). Similar one-dimensional model was also used by Cui et al (2005) to describe the heat and water flow in a silty soil. In this model, the transient equation of liquid water and water vapour is given as follows.

$$
\frac{\partial h_{w}}{\partial t}=C_{w} \frac{\partial}{\partial \mathrm{z}}\left(k_{w} \frac{\partial h_{w}}{\partial \mathrm{z}}\right)+C_{v} \frac{\partial}{\partial \mathrm{z}}\left(D_{v} \frac{\partial P_{v}}{\partial \mathrm{z}}\right)
$$

where $t(\mathrm{~s})$ is the time, $z(\mathrm{~m})$ the elevation, $h_{w}(\mathrm{~m})$ the total hydraulic head (the sum of capillary head and elevation head $z), P_{v}(\mathrm{kPa})$ the vapour pressure, $C_{w}(\mathrm{~m})$ and $C_{v}$ $\left(\mathrm{m}^{4} \mathrm{~kg}^{-1}\right)$ the modulus of volume change with respect to liquid phase and vapour phase respectively, $D_{v}\left(\mathrm{~kg} \mathrm{~m} \mathrm{kN}^{-1} \mathrm{~s}^{-1}\right)$ the diffusion coefficient of water vapour through soil. Vapour pressure $P_{v}$ may be related to the pressure head $h_{w}$ by Kelvin's equation. $k_{w}$ 
is the water hydraulic conductivity depending on soil suction.

The calculation of the vapour pressure $P_{v}$ in Eq. 1 depends on the saturated vapour pressure $P_{v s}$ and the soil temperature $T$. Hence, the temperature profile of the soil must be determined simultaneously. Wilson (1994) used Eq. 2 to describe the heat flow due to both conductivity and latent heat diffusion.

$$
C_{h} \frac{\partial T}{\partial t}=\frac{\partial}{\partial \mathrm{z}}\left(\lambda \frac{\partial T}{\partial \mathrm{z}}\right)+L_{v} \frac{P+P_{v}}{P} \frac{\partial}{\partial \mathrm{z}}\left(D_{v} \frac{\partial P_{v}}{\partial \mathrm{z}}\right)
$$

where $C_{h}\left(\mathrm{~J} \mathrm{~m}^{-3}{ }^{\circ} \mathrm{C}^{-1}\right)$ is the volumetric specific heat capacity, representing the thermal storage capacity of the volume element considered. $\lambda\left(\mathrm{J} \mathrm{s}^{-1} \mathrm{~m}^{-1}{ }^{\circ} \mathrm{C}^{-1}\right)$ is the thermal conductivity of soil. $L_{v}\left(\mathrm{~J} \mathrm{~kg}^{-1}\right)$ is the latent heat coefficient of vaporisation of water: $L_{v}=4.186 \times 10^{3}(607-0.7 T)$, where $T$ is the temperature in ${ }^{\circ} \mathrm{C}$.

\section{Energy analysis method to define the soil-atmosphere boundary}

The energy analysis method is based on the consideration of the energy balance in the earth-atmospheric system which can be presented as:

$$
R_{n}=G+H+L E
$$

where $\mathrm{G}\left(\mathrm{W} \mathrm{m}^{-2}\right)$ is the ground heat transfer (positive when energy is transferred to the subsurface and negative when energy is transferred to the atmosphere). $\mathrm{H}\left(\mathrm{W} \mathrm{m}^{-2}\right)$ is the sensitive heat transfer (positive when energy is used to warm the air and negative when the air loses energy due to cooling). LE $\left(\mathrm{W} \mathrm{m}^{-2}\right)$ is the latent energy transfer (positive for evaporation and negative for condensation). $R_{\mathrm{n}}\left(\mathrm{W} \mathrm{m}^{-2}\right)$ is the net radiation at the soil surface and can be estimated from the incoming solar radiation $R_{s i}$ $\left(\mathrm{W} \mathrm{m}^{-2}\right)$ and the long-wave radiation emitted by soil surface and atmosphere:

$$
R_{n}=(1-\mathrm{A}) R_{\mathrm{si}}-\varepsilon_{s} \sigma T_{s}^{4}+\varepsilon_{a} \sigma T_{a}^{4}
$$

where $A$ is the soil albedo; $\varepsilon_{s}$ is the soil-surface emissivity; $\varepsilon_{\mathrm{a}}$ is the air emissivity; $\sigma$ is the Stefan-Boltzmann constant $\left(5.67 \times 10^{-8} \mathrm{~W} \mathrm{~m}^{-2} \mathrm{~K}^{-4}\right) ; T_{s}(\mathrm{~K})$ and $T_{\mathrm{a}}(\mathrm{K})$ are the soil-surface and air temperature, respectively.

In the work of Cui et al. (2005), the water flux at the soil surface was determined using the potential evapotranspiration calculated using the Penman method. The repartition of the net solar radiation $R_{n}$ on the soil surface was done by assuming a constant ratio $G / R_{n}(G$ is the soil heat flux) and a constant ratio $H / L E$ ( $H$ is the sensitive heat; LE is the latent heat flux). This method has the drawback of not considering the soil surface properties such as the roughness. In this work, a more explicit approach was adopted, without assumption of various constant ratios. Water and heat transfers in the upper boundary between soil and atmosphere are modelled using Eq. 5 and 6, which are based on the Prandtl approach and similarity theory (Monin and Obukhov, 1954): 


$$
\begin{gathered}
H=\frac{\rho_{a} C_{p a}\left(\mathrm{~T}_{\mathrm{s}}-T_{a}\right)}{r_{\mathrm{T}}} \\
L E=\frac{L_{\mathrm{v}} M_{w}\left(p_{v z 0}-p_{v z a}\right)}{R T r_{\mathrm{v}}}
\end{gathered}
$$

Where $\mathrm{H}$ is the sensitive heat; $\mathrm{LE}$ is the latent heat flux; $\rho_{\mathrm{a}}\left(\mathrm{kg} \mathrm{m}^{-3}\right)$ is the air density; $C_{\mathrm{pa}}\left(\mathrm{J} \mathrm{kg}^{-1} \mathrm{~K}^{-1}\right)$ is the specific heat of air $\left(1.013 \times 10^{3} \mathrm{~J} \mathrm{~kg}^{-1} \mathrm{~K}^{-1}\right) ; T_{s}(\mathrm{~K})$ is the soil surface temperature; $T_{a}(\mathrm{~K})$ is the air temperature at a reference height $z_{a}(\mathrm{~m}) ; T(\mathrm{~K})$ is the average temperature: $T \approx\left(T_{a}+T_{s}\right) / 2 ; p_{v z 0}(\mathrm{~Pa})$ is the vapour pressure at the soil surface; $p_{v z a}(\mathrm{~Pa})$ is vapour pressure in the air at the reference height $z_{a}(\mathrm{~m}) ; r_{T}$ and $r_{v}$ $\left(\mathrm{s} \mathrm{m}^{-1}\right)$ are the aerodynamic resistances for the sensitive and latent heat fluxes; $M_{w}$ is the molecular mass of water $\left(0.018 \mathrm{~kg} \mathrm{~mol}^{-1}\right) ; R$ is the gas constant $\left(8.314 \mathrm{~J} \mathrm{~mol}^{-1} \mathrm{~K}^{-1}\right)$.

Eq. 5 and 6 take into account both the soil-atmosphere resistance $r_{T}$ and $r_{v}$, which depend on the wind velocity $u_{a}$, the soil-atmosphere temperature gradient $T_{s}-T_{a}$ and the vapour pressure gradient $p_{v z 0}-p_{v z a}$. It is generally assumed that $r_{T}=r_{v}=r_{a}$ and the aerodynamic resistances $r_{a}$ can be calculated using the approach proposed by $\mathrm{Xu}$ and Qiu (1997) and Xu et al. (1999):

$$
\mathrm{r}_{\mathrm{a}}=\frac{1}{k \mathrm{u}_{*}}\left[\ln \left(\frac{z_{\mathrm{a}}}{z_{0}}\right)-\psi_{H}\left(\frac{z_{\mathrm{a}}}{L^{\prime}}\right)+\psi_{H}\left(\frac{z_{0}}{L^{\prime}}\right)\right]
$$

where $u_{*}\left(\mathrm{~m} \mathrm{~s}^{-1}\right)$ is the friction velocity; $L^{\prime}(\mathrm{m})$ is the Obukhov length; $\psi_{H}$ is the stability function. $u *$ is calculated from a logarithmic wind profile $u_{*}=u_{z} \mathrm{k} / \operatorname{Ln}\left(z / z_{0}\right)$, where $\mathrm{u}_{\mathrm{z}}\left(\mathrm{m} \mathrm{s}^{-1}\right)$ is the wind speed measured at an elevation of $\mathrm{z}(\mathrm{m}) ; z_{0}(\mathrm{~m})$ is the roughness length. $\mathrm{k}$ is a constant taken in general equal to 0.41 . The Obukhov length $L^{\prime}$ is calculated by

$$
L^{\prime}=-\left(\frac{\rho_{a} C_{p a} \mathrm{u}_{*}^{3} T_{a}}{k g H}\right)
$$

Where $\mathrm{k}$ is the same constant as in Eq. 7. The stability function for the case of unstable stratification $\left(L^{\prime}<0\right.$, in the sense of turbulent flow) is given by

$$
\psi_{H}=2 \ln \left(\frac{1+x^{2}}{2}\right) \quad, \quad \mathrm{x}=\left(\frac{1-16 \mathrm{z}}{\mathrm{L}^{\prime}}\right)^{1 / 4}
$$

and for the case of stable stratification $\left(L^{\prime}>0\right.$, in the sense of laminar flow)

$$
-\psi_{H}=\left(1+\frac{2 a z}{3 L^{\prime}}\right)^{3 / 2}+b\left(\frac{z}{L^{\prime}}-\frac{c}{d}\right) \exp \left(-d \frac{z}{L^{\prime}}\right)+\frac{b c}{d}-1
$$

According to $\mathrm{Xu}$ and Qiu (1997), $\mathrm{a}=1, \mathrm{~b}=0.667, \mathrm{c}=5$ and $\mathrm{d}=0.35$.

As the sensitive heat $H$ is involved in Eq. 8 to determine the Obukhov length $L$, an iteration process is needed in the resolution of the above equations. When $H$ and $L E$ are known, the soil heat flux $G$ can be then determined from the energy 
balance equation (Eq. 3).

The soil-atmosphere boundary condition is then totally defined by the latent heat flux $L E$ and soil heat flux $G$.

\section{Numerical methods}

In this study, only changes in soil temperature, water content and suction along the central axis of the embankment were simulated. The recorded meteorological data were used to set the soil-atmosphere boundary condition. The heat and mass flow equations (Eq. 1 and Eq. 2) were solved using the finite difference method by taking the origin of the vertical axis $\mathrm{z}$ at the base of the embankment. For the resolution, water flow equation (Eq. 1) was first rewritten as:

$$
\frac{\partial h_{w}}{\partial t}=C_{w} \frac{\partial k_{w}}{\partial \mathrm{z}} \frac{\partial h_{w}}{\partial \mathrm{z}}+C_{w} k_{w} \frac{\partial^{2} h_{w}}{\partial \mathrm{z}^{2}}+C_{v} \frac{\partial D_{v}}{\partial \mathrm{z}} \frac{\partial P_{v}}{\partial \mathrm{z}}+C_{v} D_{v} \frac{\partial^{2} P_{v}}{\partial \mathrm{z}^{2}}
$$

and the corresponding difference equation is

$$
\begin{aligned}
& \frac{h_{w(i, j+1)}-h_{w(i, j)}}{\Delta t}= \\
& C_{w} \frac{k_{w(i+1, j)}-k_{w(i-1, j)}}{2 \Delta \mathrm{z}} \cdot \frac{h_{w(i+1, j)}-h_{w(i-1, j)}}{2 \Delta \mathrm{z}}+C_{w} k_{w} \frac{h_{w(i+1, j)}-2 h_{w(i, j)}+h_{w(i-1, j)}}{\Delta \mathrm{z}^{2}}+ \\
& C_{v} \frac{D_{v(i+1, j)}-D_{v(i-1, j)}}{2 \Delta \mathrm{z}} \cdot \frac{P_{v(i+1, j)}-P_{v(i-1, j)}}{2 \Delta \mathrm{z}}+C_{v} D_{v} \frac{P_{v(i+1, j)}-2 P_{v(i, j)}+P_{v(i-1, j)}}{\Delta \mathrm{z}^{2}}
\end{aligned}
$$

where $i$ is the distance increment number in the $z$ direction , $j$ is the time increment number, $\Delta \mathrm{z}$ is the distance step increment, $\Delta t$ is the time step increment .

In the same fashion, heat flow equation (Eq. 2) was rewritten as:

$$
C_{h} \frac{\partial T}{\partial t}=\frac{\partial \lambda}{\partial \mathrm{z}} \frac{\partial T}{\partial \mathrm{z}}+\lambda \frac{\partial^{2} T}{\partial \mathrm{z}^{2}}+L_{v} \frac{P+P_{v}}{P}\left(\frac{\partial D_{v}}{\partial \mathrm{z}} \frac{\partial P_{v}}{\partial \mathrm{z}}+D_{v} \frac{\partial^{2} P_{v}}{\partial \mathrm{z}^{2}}\right)
$$

and the corresponding difference equation is

$$
\begin{aligned}
& C_{h} \frac{T_{(i, j+1)}-T_{(i, j)}}{\Delta t}= \\
& \frac{\lambda_{(i+1, j)}-\lambda_{(i, j)}}{\Delta \mathrm{z}} \cdot \frac{T_{(i+1, j)}-T_{(i, j)}}{\Delta \mathrm{z}}+\lambda \frac{T_{(i+1, j)}-2 T_{(i, j)}+T_{(i-1, j)}}{\Delta \mathrm{z}^{2}}+ \\
& L_{v} \frac{P+P_{v}}{P}\left(\frac{D_{v(i+1, j)}-D_{v(i, j)}}{\Delta \mathrm{z}} \cdot \frac{P_{v(i+1, j)}-P_{v(i, j)}}{\Delta \mathrm{z}}+D_{v} \frac{P_{v(i+1, j)}-2 P_{v(i, j)}+P_{v(i-1, j)}}{\Delta \mathrm{z}^{2}}\right)
\end{aligned}
$$

At soil surface $(\mathrm{i}=1)$, the boundary condition are defined by surface temperature $\mathrm{T}(1)$, surface vapor pressure $P_{v}(1)$ and surface water head $h_{w}(1)$. Soil temperature $T$ and water head $h_{w}$ at time $t=j+1$ can be calculated from the values at time $t=j$ using the two finite difference equations above. Figure 10 presents the calculation scheme for the numerical resolution.

In order to obtain a stable and accurate solution, a small point distance $\Delta \mathrm{z}$ was used in both the near surface zone and the zone near the base where hydraulic gradient was large when evaporation or infiltration was significant. In the simulation, $\Delta \mathrm{z}=$ $5 \mathrm{~mm}$ for depth $0-20 \mathrm{~cm}$ and $505-525 \mathrm{~cm} ; \Delta \mathrm{z}=10 \mathrm{~mm}$ for depth $20-50 \mathrm{~cm}$ and $475-505 \mathrm{~cm} ; \Delta \mathrm{z}=50 \mathrm{~mm}$ for depth $50-475 \mathrm{~cm}$. A fixed time step $\Delta t$ was 
adopted: $0.5 \mathrm{~s}$.

\section{Initial values and boundary conditions}

The initial soil temperature and volumetric water content profiles were determined by the measured temperature and volumetric water content along the central axis in the night of $31^{\text {st }}$ March, 2005; a linear relationship was assumed between two neighbouring measurement points. Because the volumetric water content of the surface soil was not monitored in the field, an initial value of $20 \%$ was assumed, which can affect the simulation results during several days, as shown later.

The soil-atmosphere boundary is defined by the energy analysis method given in the last section from the measured meteorological data (air temperatures at $1.0 \mathrm{~m}$, wind speed at $1.0 \mathrm{~m}$, relative humidity at $1.0 \mathrm{~m}$ above the embankment surface, solar radiation and precipitation). The measured temperature and volumetric water content near the base were used to define the bottom boundary condition.

\section{Soil-atmosphere interface parameters}

As Eq. 3 and 4 indicated, soil albedo $A$ plays a major role in the energy balance. Albedo depends mainly on the volumetric water content $\theta_{\mathrm{s}}$, decreasing when $\theta_{\mathrm{s}}$ increases. In this work, the soil albedo $A$ was determined using the expression proposed by Passerat de Silans et al. (1989):

$$
\begin{aligned}
& \mathrm{A}\left(\theta_{\mathrm{s}}\right)=0.1 \quad \text { for } \theta_{\mathrm{s}} \geq 0.3 \\
& \mathrm{~A}\left(\theta_{\mathrm{s}}\right)=0.25 \quad \text { for } \theta_{\mathrm{s}}<0.1 \\
& \mathrm{~A}\left(\theta_{\mathrm{s}}\right)=0.25-0.75\left(\theta_{\mathrm{s}}-0.1\right) \quad \text { for } 0.3 \geq \theta_{\mathrm{s}} \geq 0.1
\end{aligned}
$$

A constant value as 0.90 was taken for emissivity $\varepsilon_{\mathrm{s}}$. The emissivity $\varepsilon_{\mathrm{a}}$ was estimated from the vapour pressure $P_{\mathrm{vza}}(\mathrm{Pa})$ and air temperature $T_{a}\left({ }^{\circ} \mathrm{C}\right)$ at the reference elevation $\mathrm{z}_{\mathrm{a}}$ (Idso, 1981):

$$
\varepsilon_{\mathrm{a}}=0.70+0.5 .95 p_{\text {vza }} \exp \left(\frac{1500}{T_{a}+273.1}\right)
$$

The roughness length $z_{0}$ depends on the roughness of the bare soil surface. Generally, a bigger roughness length $z_{0}$ results in a smaller resistance $r_{a}$ and a higher latent heat $L E$ and sensitive heat $H$. In this work, $z_{0}$ was determined by a calibration phase. The fitting was made by a maximum likelihood method, which compared measured and simulated soil-surface temperature in the first five days. It was found that a value of $0.15 \mathrm{~mm}$ was suitable. This value is very close to the value of $0.14 \mathrm{~mm}$ used by Melayah and Bruckler (1996) in an analysis of a bare soil surface.

\section{Soil parameters}

A set of thermal-hydro-mechanical parameters was selected for each soil used to construct the embankment. The water retention curve expressing the relationship between suction s $(\mathrm{kPa})$ and volumetric water content $\theta_{w}$ was described using Eq. 13 
(see Cui et al. 2005):

$$
\theta_{w}=\frac{\theta_{w s}-\theta_{r}}{1+\left(\frac{\theta_{w s}-\theta_{r}}{\theta_{w 1}-\theta_{r}}-1\right)\left(\frac{s}{s_{1}}\right)^{\varsigma}}+\theta_{r}
$$

where $\theta_{w s}$ is the volumetric water content in the saturated state; $\theta_{r}$ is the residual volumetric water content; $\theta_{w 1}$ is the value of water content corresponding to a reference suction $s_{1}(\mathrm{kPa}) . \varsigma$ is a parameter controlling the shape of the water retention curve. The fitted values from field suction and volumetric water content measurements were $\theta_{\mathrm{ws}}=0.33, \theta_{\mathrm{r}}=0.05, \theta_{\mathrm{wl}}=0.26, s_{1}=$ $30 \mathrm{kPa}, \zeta=1.0$ for the upper soil SNEC and $\theta_{\mathrm{ws}}=0.44, \theta_{\mathrm{r}}=0.05, \theta_{\mathrm{wl}}=0.26, s_{l}=$ $50 \mathrm{kPa}$ for the lower soil A28 (Fig. 10). The field data show significant scattering; that must be mainly related to the heterogeneity revealed by the soil density control (Fig. 3). Indeed, laboratory tests on soil A28 using osmotic suction control method (see Cui et al. 1996, Delage et al. 1998, Delage and Cui 2008, Blatz et al. 2008, Tang et al. 2010) for two dry densities $\left(\rho_{\mathrm{d}}=1.45 \mathrm{Mg} \mathrm{m}^{-3}\right.$ and $\rho_{\mathrm{d}}$ $=1.85 \mathrm{Mg} \mathrm{m}^{-3}$ ) showed significant density effect on the water retention curve (see Figure 11). It was therefore quite difficult for the parameters determination. One of the possible methods would be to normalise the data as respected to the soil density but as mentioned before some technical problems of the equitensiometers for suction measurement were suspected, and therefore the authors prefer adopting a single water retention curve for each soil in this study. Note also that the hysteresis in the water retention curves was not accounted for.

The hydraulic conductivity-suction relationship $k_{w}(s)$ presented by Cui et al. (2005) was adopted to calculate the hydraulic conductivity $k_{w}$ :

$$
k_{w}=\frac{k_{s}}{1+\left(\frac{k_{s}}{k_{w 1}}-1\right)\left(\frac{s}{s_{1}}\right)^{\xi}}
$$

where $k_{s}\left(\mathrm{~m} \mathrm{~s}^{-1}\right)$ is the water permeability at suction $s=0 ; k_{w l}\left(\mathrm{~m} \mathrm{~s}^{-1}\right)$ is the hydraulic conductivity corresponding to a reference suction $s_{1}(\mathrm{kPa}) ; \xi$ is a parameter. The parameters for soil SNEC were estimated based on the laboratory tests conducted by Mantho (2005) on a similar soil (Boissy-le-Chatêl silt belonging also to lean clay (CL) following the ASTM unified soil classification system; the water permeability at saturated state is about $10^{-8} \mathrm{~m} \mathrm{~s}^{-1}$ at a lower dry density of $1.6 \mathrm{Mg} \mathrm{m}^{-3}$ ), and they were $\mathrm{k}_{\mathrm{s}}=1.5 \times 10^{-9} \mathrm{~m} \mathrm{~s}^{-1}, \mathrm{k}_{\mathrm{w} 1}=1.15 \times 10^{-10} \mathrm{~m} \mathrm{~s}^{-1}, \mathrm{~s}_{1}=40 \mathrm{kPa}$ and $\xi=1.25$. For soil A28, as it was less compacted than soil SNEC, its water permeability at saturated state was taken slightly higher than that of soil SNEC: $\mathrm{k}_{\mathrm{s}}=6 \times 10^{-9} \mathrm{~m} \mathrm{~s}^{-1}$; the other parameters were kept the same: $\mathrm{k}_{\mathrm{w} 1}=1.15 \times 10^{-10} \mathrm{~m} \mathrm{~s}^{-1}, \mathrm{~s}_{1}=40 \mathrm{kPa}$ and $\xi=1.25$.

The volumetric specific heat capacity $C_{h}\left(\mathrm{~J} \mathrm{~m}^{-3}{ }^{\circ} \mathrm{C}^{-1}\right)$ was determined using Eq. 15 proposed by de Vries (1963):

$$
C_{h}=C_{s} \theta_{s}+C_{w} \theta_{w}+C_{a} \theta_{a}
$$

where $\mathrm{C}_{\mathrm{s}}, \mathrm{C}_{\mathrm{w}}$ and $\mathrm{C}_{\mathrm{a}}$ are the volumetric specific heat capacity of soil solids $(2.24 \mathrm{x}$ $\left.10^{6} \mathrm{~J} \mathrm{~m}^{-3}{ }^{\mathrm{o}} \mathrm{C}^{-1}\right)$, liquid water $\left(4.15 \times 10^{6} \mathrm{~J} \mathrm{~m}^{-3}{ }^{\mathrm{o}} \mathrm{C}^{-1}\right)$ and air $\left(1.34 \times 10^{3} \mathrm{~J} \mathrm{~m}^{-3}{ }^{\mathrm{o}} \mathrm{C}^{-1}\right.$, neglected) respectively; $\theta_{s}, \theta_{w}$ and $\theta_{a}$ are the volumetric contents of soil solids, water and air, respectively. The thermal conductivity of soil $\lambda\left(\mathrm{W} \mathrm{m}^{-1}{ }^{\mathrm{o}} \mathrm{C}^{-1}\right)$ was determined using Eq. 16 proposed by de Vries (1963): 


$$
\lambda=\frac{f_{s} \theta_{s} \lambda_{s}+f_{w} \theta_{w} \lambda_{w}+f_{a} \theta_{a} \lambda_{a}}{f_{s} \theta_{s}+f_{w} \theta_{w}+f_{a} \theta_{a}}
$$

where $\lambda_{s}, \lambda_{w}$ and $\lambda_{a}$ are the thermal conductivity of solid $\left(6.0 \mathrm{~W} \mathrm{~m}^{-1}{ }^{\mathrm{o}} \mathrm{C}^{-1}\right)$, water $\left(0.57 \mathrm{~W} \mathrm{~m}^{-1} \mathrm{o}^{-1}\right)$ and air $\left(0.025 \mathrm{~W} \mathrm{~m}^{-1} \mathrm{C}^{-1}\right.$, neglected $)$ respectively; $f_{s}, f_{w}$ and $f_{a}$ are the weight coefficients for solid, water and air respectively, they are determined by the method proposed by Wilson et al. (1994, see also Fredlund and Rahardjo 1993): $f_{w}=1.0, f_{s}=0.25$ and $f_{a}=1.5$.

\section{Simulation results and analysis}

Figure 12 compares the simulated and measured soil temperatures at the embankment surface. On the whole, satisfactory agreement was obtained between the measured and calculated data. Nevertheless, some problems can be observed: the calculated maximum temperature is about $35^{\circ} \mathrm{C}$ whilst the measured maximum temperature is about $40^{\circ} \mathrm{C}$; in some periods $\left(26^{\text {th }}\right.$ February to $23^{\text {rd }}$ March, 2005, and $1^{\text {st }}$ to $8^{\text {th }}$ May, 2005, for instance), the calculated temperatures are much higher than the measured ones; in some other periods ( $8^{\text {th }}$ to $12^{\text {th }}$ April and $8^{\text {th }}$ to $14^{\text {th }}$ May, 2005, for instance) it is the inverse. Therefore the simulation gave a good general trend of temperature variations only, and it is difficult to obtain accurate simulations over the whole monitoring period. Note that the constant calculated temperature during a period in July was due to the lack of volumetric water content measurements (see Figure 6).

Figure 13 presents the soil temperature changes at four depths: 34, 133, 290 and $412 \mathrm{~cm}$. An obvious difference can be observed: the measured temperatures show a decrease in the cold season from December, 2004, to March 2005, and increase afterwards; the decrease-increase transition being function of the depth as observed in Figure 7. This transition is less evident for the calculated temperatures.

Figure 14a shows the simulated volumetric water content at $34 \mathrm{~cm}$. It is observed that the variation was quite small and on the whole the simulation was in accordance with the field data. The same observation can be made for the other depths (Figure 14b-d). Because no field data was available in the near surface zone (shallower than $34 \mathrm{~cm}$ ), no comparison was possible for this zone. That is why only simulation results are presented in Figure 15, at 5 selected depths $(0,2,5,10$ and $20 \mathrm{~cm})$ in the near surface zone. It can be observed that at $20 \mathrm{~cm}$ depth, the variation of volumetric water content was also small; By contrast, in the shallower soil, the variation is very clear. The difference between the first four depths $(0,2,5$ and $10 \mathrm{~cm})$ seems to be negligible. Significant variations are observed during the periods of $17^{\text {th }}$ and $23^{\text {rd }}$ December, 2004; $11^{\text {th }}$ February, 2005; $13^{\text {th }}$ and $24^{\text {th }}$ April, 2005; $4^{\text {th }}, 14^{\text {th }}$ and $30^{\text {th }}$ May, 2005; $4^{\text {th }}$ and $24^{\text {th }}$ July, 2005; $13^{\text {th }}$ August, 2005; consistent with the precipitation records.

In Figure 15, the calculated results do not seem to be affected by the initial value set $(20 \%)$. Actually, in the preliminary analyses performed to the aim of verifying the influence of the initial conditions, the effect of the initial value was almost erased after one day, hence justifying the choice for the simulation presented.

Figure 16 presents the comparison between the calculated and measured soil 
suction (negative pore pressure) variations, at $61 \mathrm{~cm}$ depth (the first level for suction measurement). Significant differences were observed. The field data showed a low variation with an average value of about $20 \mathrm{kPa}$. On the contrary, the calculation gave a quasi constant suction of about $40 \mathrm{kPa}$, in agreement with the low volumetric water content variations calculated (see Figure 13). For deeper levels the calculation also showed negligible suction variations and the results are not presented. As for volumetric water content variation, the suction variations in the zone shallower than $61 \mathrm{~cm}$ were calculated for 5 different depths $(0,2,5,10$ and $20 \mathrm{~cm})$. Significant variations were observed for $0,2,5$ and $10 \mathrm{~cm}$ depths; the variations were smaller at $20 \mathrm{~cm}$ depths. Again, theses variations are correlated with the precipitations records.

Note that when calculating the soil hydraulic conductivity $\mathrm{k}_{\mathrm{w}}$, if the volumetric water content $\theta_{\mathrm{w}}$ is close to its residual value $\theta_{\mathrm{wr}}$, suction becomes very high leading to a value of $\mathrm{k}_{\mathrm{w}}$ close to 0 . This would result in numerical problem when determining the boundary value of water head. To avoid this problem, in the calculations, a minimum value of $10^{-11} \mathrm{~m} / \mathrm{s}$ was set for $\mathrm{k}_{\mathrm{w}}$. This is probably the reason for the cut-off values observed in Figure 15 and Figure 16.

\section{Conclusions}

An experimental embankment was constructed in Rouen, France. Significant instrumentation was installed, including a meteorological station on the embankment surface, soil temperature, soil volumetric water content, soil negative water pressure (suction) and soil vertical and horizontal displacements, in various depths. This enabled the analysis of the interaction between atmosphere and embankment soil using the first period monitoring data over about 9 months prior to water flooding from the base.

According to the embankment design, soil A28 was designed to be loosely compacted at $80 \%$ optimum in order to emphasise its collapsible behaviour upon wetting; by contrast, soil SNEC was densely compacted at $95 \%$ optimum in order to expose its swelling behaviour. The results of density control showed that the actual densities were far from the designed values. This reflects the common difficulty encountered in soil compaction work in field conditions.

Because of the low permeability of the two constitutive compacted soils, the effect of evaporation and precipitation on soil volumetric water content was limited to a certain depth. Indeed, the field data showed that even at the first measurement level for volumetric water content (layer 14 at $34 \mathrm{~cm}$ depth), only a fluctuation smaller than $2 \%$ was recorded. According to the simulation results, the climatic effect on volumetric water content was limited to $10 \mathrm{~cm}$ depth.

In terms of changes in suction or negative pore pressure, it appears that all depths were affected. This suggests that suction was more sensitive to climatic changes than volumetric water content. Nevertheless, the field data and the simulation results showed that the most significant variations were in the near surface area: the variations were very limited in the soil deeper than $10 \mathrm{~cm}$.

As far as the temperature changes are concerned, it appears that during 24 hours, it was limited to $34 \mathrm{~cm}$ depth. But this limit depth changed over a longer period: if a five-month period is considered, the soil temperature changes involved all the depths. 
Energy analysis method has been found to be an efficient method for the definition of the soil-atmosphere boundary condition. Indeed, only the easily measured meteorological data were required to predict changes in suction, water content and temperature. In practice, this kind of prediction has obviously significant economical and environmental impacts because direct monitoring of the suction and the water content are known to be difficult.

Comparison of simulation results with field measurements shows that an approach combining the soil-atmosphere interaction analysis and a coupled heat-water flow model can be used to calculate the water content, temperature and suction of the soil at any time. As all numerical modelling work, the main difficulty is the determination of model parameters. In this work, for the determination of roughness length $z_{0}$, a calibration was carried out using the first five-day field data. For the initial volumetric water content at the embankment surface, an estimated value of $20 \%$ was given. The simulation results showed that the numerical approach adopted is able to auto-regulate itself over a short time.

It must be mentioned however that the adopted one-dimensional model represents a simplistic method because the geometry of the experimental embankment. It seems to be valid for the central axis. For a full geometry analysis, a two-dimensional or three-dimensional model is necessary. Note also that the work performed has benefited from the relatively rich data; when making an analysis of a real geotechnical embankment, the boundary conditions are certainly more complicated and less available data are expected; as a result, the analysis would be more difficult.

\section{Acknowledgements}

The authors are grateful to ParisTech for the grant attributed to the first author. The second author also thanks the support by the Chutian scholar program. 


\section{References}

Arbizzi S., Kreziak C., Barraud D., Larrère F., Souvignet S. and Nagel B. 2008. Analyse d'une base de données "pathologies liées à la sécheresse" et mise en relation avec les sols support. International Symposium on Drought and Constructions - SEC2008, Paris, LCPC, 385-391.

Blatz J., Cui Y.J. and Oldecop L. 2008. Vapour Equilibrium and Osmotic Technique for Suction Control. Geotechnical and Geological Engineering, Special Issue on "Laboratory and Field Testing of Unsaturated Soils". 26(6), 661-673.

Bogaard T.A. and Van Asch Th.W.J. 2002. The role of the soil moisture balance in the unsaturated zone on movement and stability of the Beline landslide, France. Earth Surface Processes and Landforms, 27, 1177-1188.

Borde M. and Desprès R. 2008. Exemples concrets et illustrés des effets des périodes de sécheresse prolongée sur des constructions situées sur des sols argileux à fort aléa. International Symposium on Drought and Constructions - SEC2008, Paris, LCPC, 367-375.

Camillo, P. J., and Gurney, R. J., 1986. A Resistance Parameter for Bare-Soil Evaporation Models. Soil Science, 141(2), 95-105.

Chanzy, A., and Bruckler, L., 1993. Significance of Soil Surface Moisture with Respect to Daily Bare Soil Evaporation. Water Resources Research, 29(4), 1113-1125.

Choudhury, B.J., Reginato, R.J. and Idso, S.B. 1986. An analysis of infrared temperature observations over wheat and calculation of latent heat flux. Agric. Forest Meteorol., 37, 75-88.

Cui Y. J. and Delage P. 1996. Yielding and plastic behaviour of an unsaturated compacted silt. Géotechnique , 46(2), 291-311.

Cui, Y.J., Lu Y.F., Delage P. and Riffard M. 2005. Field simulation of in site water content and temperature changes due to ground-atmospheric interactions. Geotechnique, 55(7): 557-567.

Cui Y.J. and Zornberg J.G. 2008. Water balance and evapotranspiration monitoring in geotechnical and geoenviromental engineering. Geotechnical and Geological Engineering, Special Issue on "Laboratory and Field Testing of Unsaturated Soils". 26, 783-798.

Delage P., Howat M., Cui Y. J. 1998. The relationship between suction and swelling properties in a heavily compacted unsaturated clay. Engineering Geology, 50(1-2), 31-48.

Delage P. and Cui Y.J. 2008. An evaluation of the osmotic method of controlling suction. Journal of Geomechanics and Geoengineering. 3(1), 1-11.

De Vries, D. A. 1963, Thermal properties of soils, In: W. R. van Wijk (ed.), Physics of Plant Environment, North-Holland Publishing Company, Amsterdam, 210-235.

Fredlund, D.G. and Rahardjo.1993. Soil mechanics for unsaturated soils. New York :

John Wiley and Sons, Inc.

GTR 1992. Guide Technique «Réalisation des remblais et des couches de forme ». Laboratoire Central des Ponts et Chaussées (LCPC) and service d'études 
techniques des routes et autoroutes (SETRA), France.

Guyot, G., (1997), Climatologie de l'Environnement, De la plante aux écosystèmes, Collection : Enseignement des Sciences de la Vie, Masson Paris, livre réservé au biblio des sciences humaines (10 Sept., 1997)

Kondo, J., Saigusa, N., and Sato, T. 1990. A Parameterization of Evaporation from Bare Soil Surfaces. Journal of Applied Meteorology. 29(5), 385-389.

Idso, S.B. 1981. A set of equations for full spectrum and 8- to 14- $\mu \mathrm{m}$ and 10.5- to 12.5 $\mu \mathrm{m}$ thermal radiation from cloudless skies. Water Resour. Res. 17(2), 295-304.

Mahfouf, J. F., and Noilhan, J. 1991. Comparative-Study of Various Formulations of Evaporation from Bare Soil Using Insitu Data. Journal of Applied Meteorology, 30(9), 1354-1365.

Malet J.P., Vna Asch Th.W.J., Van Beek L.P.H. and Maquaire O. 2005. Forecasting the behaviour of complex landslides with a spatially distributed hydrological model. Natural Hazards and Earth System Science, 5 (1), 71-85.

Mantho, A. T. 2005. Echanges sol- Atmosphere application a la secheresse. Doctoral thesis, CERMES-ENPC, Paris, France.

Melayah, A. and Bruckler, L. 1996. Modeling the transport of water stable isotopes in unsaturated soils under natural conditions 2. Comparison with field experiments. Water Resources Research, 32 (7), 2055-2065.

Monin, A.S. and Obukhov, A.M. 1954. Basic laws of turbulent mixing in the atmosphere near the ground. Trans. Geophys. Inst. Akad. Nauk. USSR 151, 163-187.

Passerat de Silans , A. , Bruckler, L., Thony, J. L. and Vauclin, M. 1989. Numerical modeling of coupled heat and water flows during drying in a stratified bare soil: Comparison with field observations. Journal of Hydrology, 105, 109-138.

Tang A.M., Cui Y.J., Qian L.X., Delage P. and Ye W.M. 2009. Calibration of the osmotic technique of controlling suction with respect to temperature using a miniature tensiometer. Canadian Geotechnical Journal, 47(3), 359-365.

Terlien M.T.J., Van Western C.J. and Van Asch Th.W.J. 1995. Deterministic modelling in GIS: landslide hazard assessment. In: Carrara A. \& Guzzetti F., Eds., Geographical Information Systems in assessing natural hazards. - Kluwer Academic Publishers, Rotterdam, 57-77.

Van Beek L.P.H. and Van Asch Th.W.J. 1998. A combined conceptual model for the effects of fissure-induced infiltration on slope stability. In: Hergarten S., Neugebauer H.J._Eds., Process Modelling and Landform Evolution. Springer-Verlag, Berlin, 147-169.

Vinceslas G., Sagnard N., Khay M., Ferber V. 2009. Variations d'état hydrique dans les remblais en zone inondable: instrumentation et suivi du comportement d'un remblai expérimental. Bulletin du Laboratoire des Ponts et Chaussées, 274, 5-30.

Wilson, G.W., Fredlund, D.G. and Barbour, S.L. 1994. Coupled soil-atmosphere modeling for soil evapouration. Canadian Geotechnical Journal, 31, 151-161.

Xu, Q., Zhou, B.B., Burk, S.D. and Barker E.H. 1999. An air-soil layer coupled scheme for computing surface heat fluxes. Journal of Applied Meteorology, 38, 211-223.

Xu, Q. and Qiu C.J. 1997. A variational method for computing surface heat fluxes 
from ARM surface energy and radiation balance systems. Journal of Applied Meteorology, 36 (1), 3-11.

Zornberg J.G. and McCartney J.S. 2005. Evaluation of evapotranspiration from alternative landfill covers at the Rocky Mountain Arsena. International Symposium on advanced experimental unsaturated soil mechanics, Trento, A.A. Balkema Publishers, 555-561. 


\section{List of tables}

Table 1: Physical properties of the fill materials

\section{List of figures}

Figure 1. Rouen test embankment near completion.

Figure 2. Grain size distribution curves of soils A28 and SNEC

Figure 3. Measured dry density of the embankment soils.

Figure 4. Sensors installed in the embankment; a) measurements of volumetric water content, suction and temperature, b) mearsurements of displacements.

Figure 5. Meteorological data from Dec. 7, 2004 to Aug. 19, 2005. (a) solar radiation; (b) precipitation; (c) wind speed at $1.0 \mathrm{~m}$ above embankment surface; (d) relative humidity at 1.0 $\mathrm{m}$ above embankment surface and (e) air temperature at $1.0 \mathrm{~m}$ above embankment surface.

Figure 6. Measured volumetric water content at different depths on central axis: (a) $34-133 \mathrm{~cm}$, (b) $175-346 \mathrm{~cm}$, (c) $412-527 \mathrm{~cm}$.

Figure 7. Variations of pore-pressure at different depths on the central axis: (a) 61-397 cm, (b) $412-527 \mathrm{~cm}$.

Figure 8. Variations of soil temperature at various depths on the central axis.

Figure 9. Measured temperature profiles on the central axis. (a) changes during 24 hours and (b) changes during 5 months.

Figure 10. Calculation scheme

Figure 11. Water retention curve determination based on the field data. (a) layer 6 to 14 for soil SNEC and (b) layer 1 to 5 for soil A28.

Figure 12. Temperature variations at the soil surface.

Figure 13. Comparison between simulations and measurements for the soil temperatures at four depths. (a) $34 \mathrm{~cm}$, (b) $133 \mathrm{~cm}$, (c) $290 \mathrm{~cm}$ and (d) $412 \mathrm{~cm}$.

Figure 14. Variations of soil volumetric water content: comparison between simulations and measurements for four depths. (a) $34 \mathrm{~cm}$, (b) $133 \mathrm{~cm}$, (c) $290 \mathrm{~cm}$ and (d) $412 \mathrm{~cm}$.

Figure 15. Simulation of volumetric water content variations at 5 near surface depths.

Figure 16. Variations of soil suction: comparison between simulations and measurements. (a) 61 cm depth and (b) 5 near surface depths. 
Table 1. Physical properties of the fill materials

\begin{tabular}{|l|c|c|}
\hline \multirow{2}{*}{ Property } & \multicolumn{2}{c|}{ Fill Materials } \\
\cline { 2 - 3 } & Soil A28 & Soil SNEC \\
\hline Plastic limit $\mathrm{w}_{\mathrm{p}}(\%)$ & 19.8 & 16.3 \\
\hline Liquid limit $\mathrm{w}_{\mathrm{L}}(\%)$ & 31.9 & 25 \\
\hline Plasticity index $\mathrm{I}_{\mathrm{p}}(\%)$ & 12.1 & 8.7 \\
\hline Methylene blue value $\mathrm{V}_{\mathrm{BS}}\left(\mathrm{g} 100 \mathrm{~g}^{-1}\right)$ & 3.24 & 2.4 \\
\hline Particle size $<80 \mu \mathrm{m}$ & $97 \%$ & $40 \%$ \\
\hline Particle size $<2 \mu \mathrm{m}$ & $25 \%$ & $15 \%$ \\
\hline Grain density $\rho_{\mathrm{s}}\left(\mathrm{Mg} \mathrm{m}^{-3}\right)$ & 2.68 & 2.66 \\
\hline $\begin{array}{l}\text { Standard proctor optimum water content } \\
\mathrm{w}_{\text {OPN }}(\%)\end{array}$ & 14.5 & 12.5 \\
\hline $\begin{array}{l}\text { Standard proctor optimum dry density } \rho_{\mathrm{dOPN}} \\
\left(\text { Mg }{ }^{-3}\right)\end{array}$ & 1.85 & 1.92 \\
\hline French GTR classification & A1-A2 & A1 \\
\hline ASTM unified soil classification & CL & CL \\
\hline
\end{tabular}

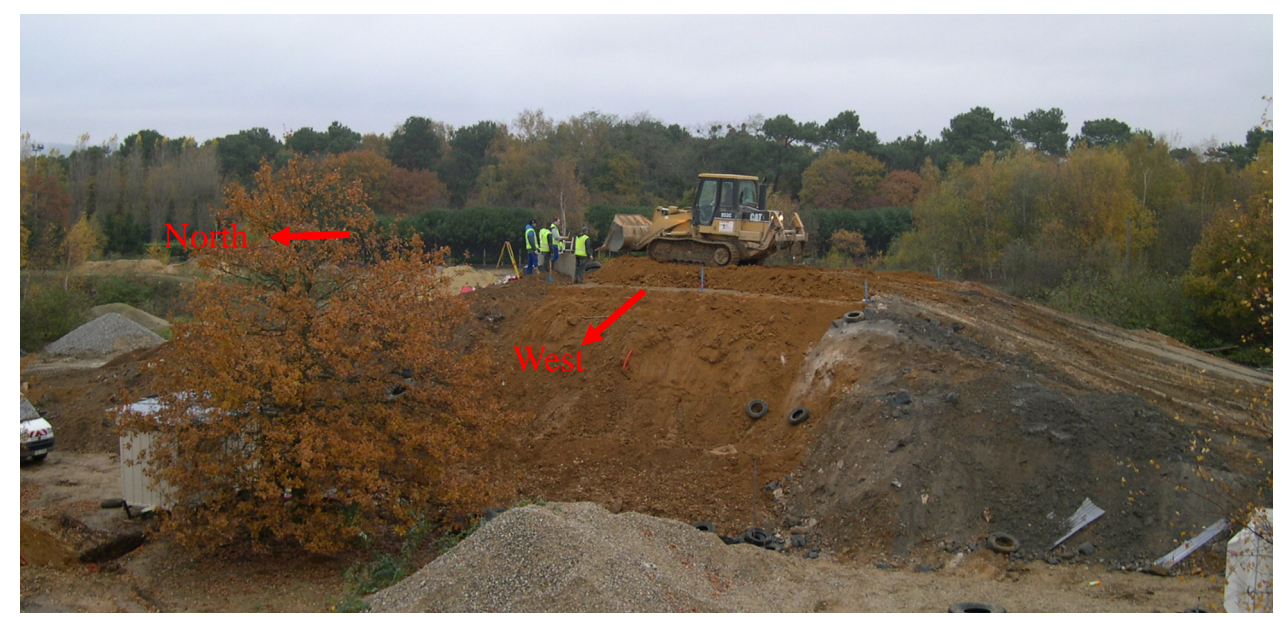

Figure 1. Rouen test embankment near completion. 


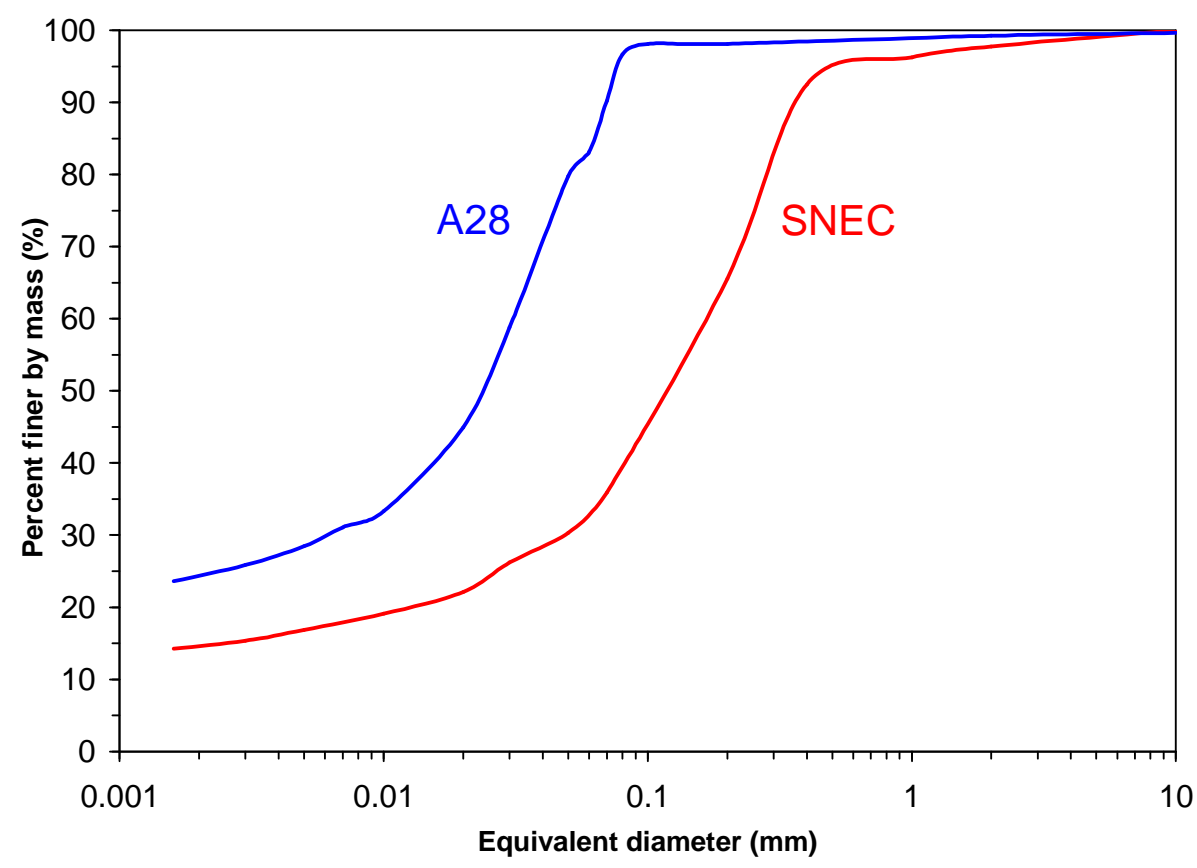

Figure 2. Grain size distribution curves of soils A28 and SNEC

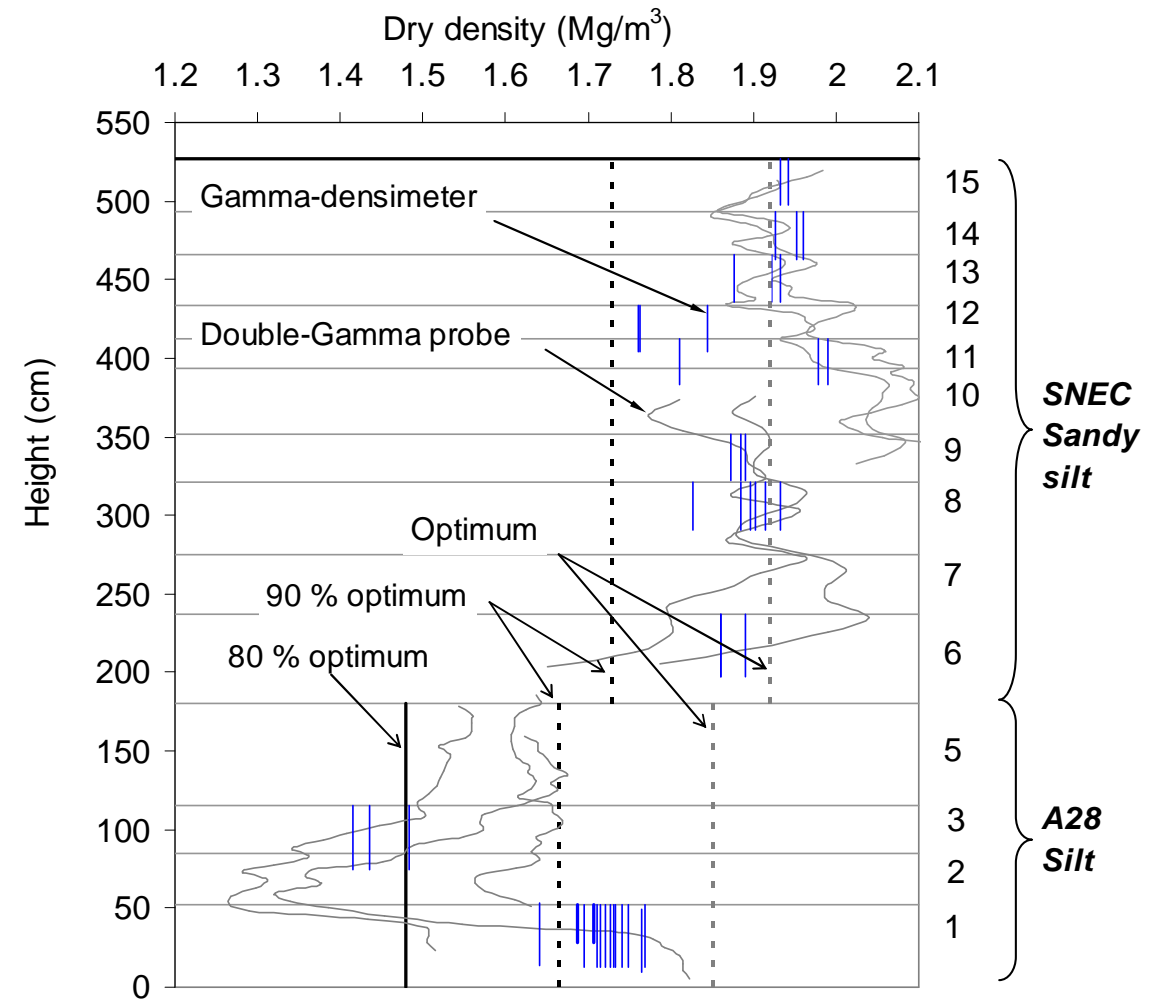

Figure 3. Measured dry density of the embankment soils. 
+ TDR probe $\left(\theta_{\mathrm{s}}\right)$

(a)

Elevation

$\times$ Equitensiometer (s)

$\Delta$ Hyperfrequency loop $\left(\theta_{\mathrm{s}}\right)$

○ Thermocouple $(\mathrm{T})$
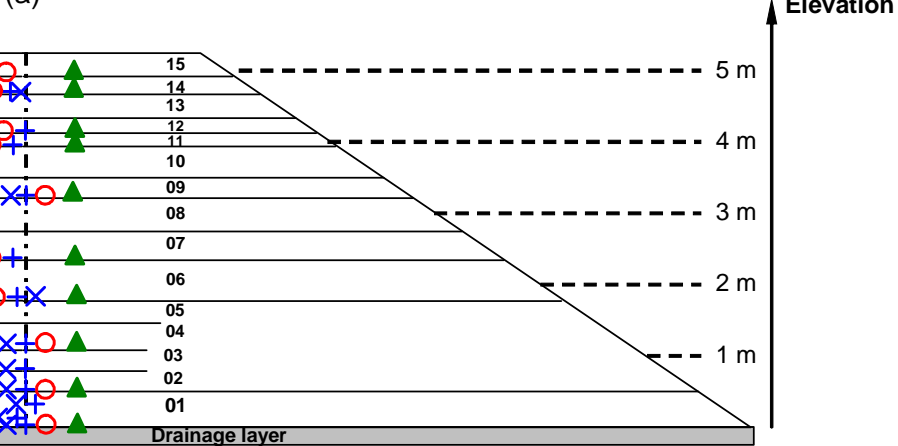

Horizontal displacement transducer

(b)

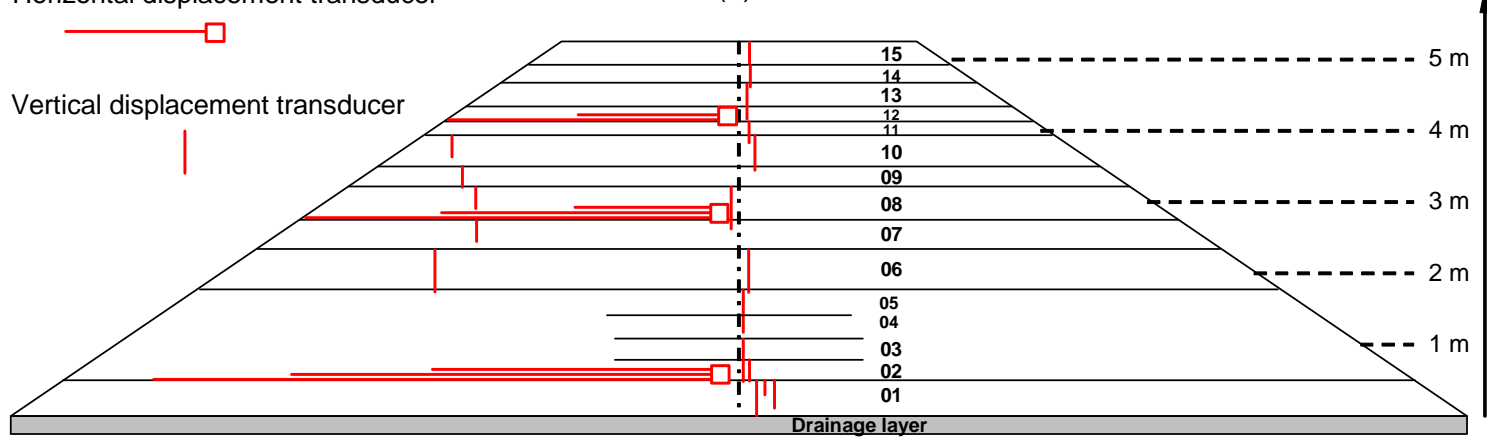

Figure 4. Sensors installed in the embankment; a) measurements of volumetric water content, suction and temperature, b) mearsurements of displacements. 
Wind speed $(\mathrm{m} / \mathrm{s})$

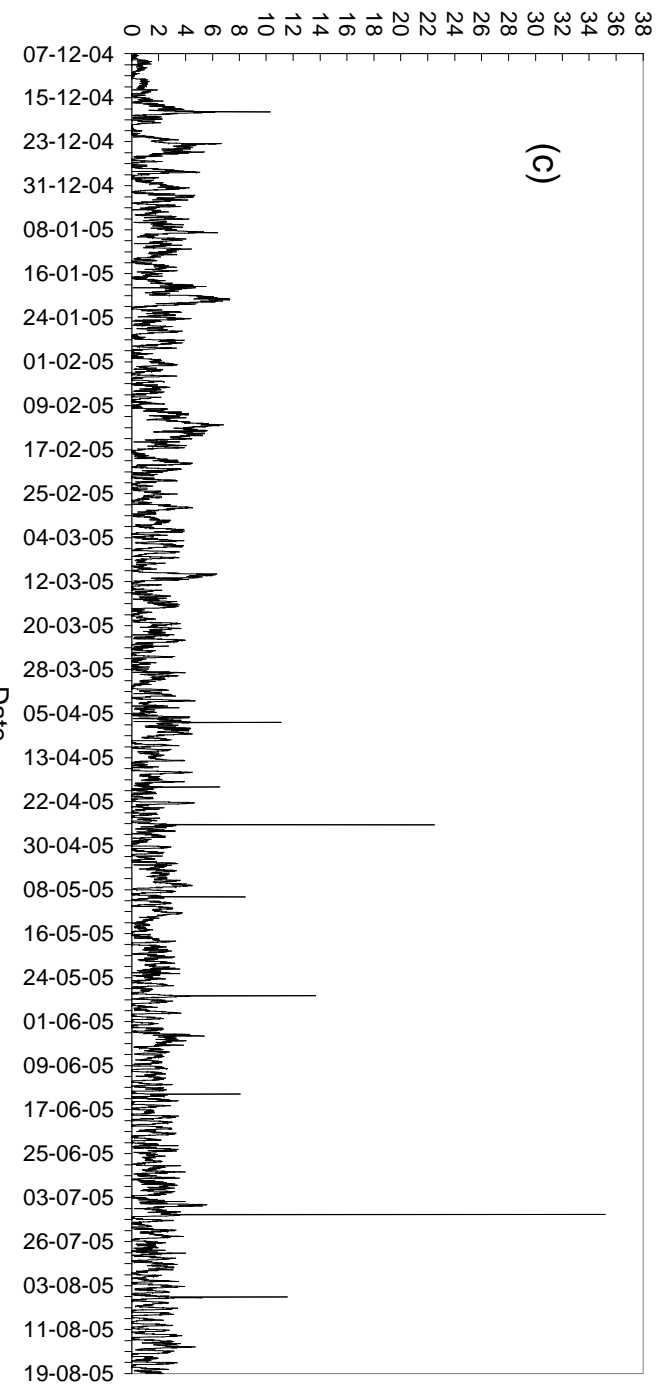

Precipitation (mm/30min)

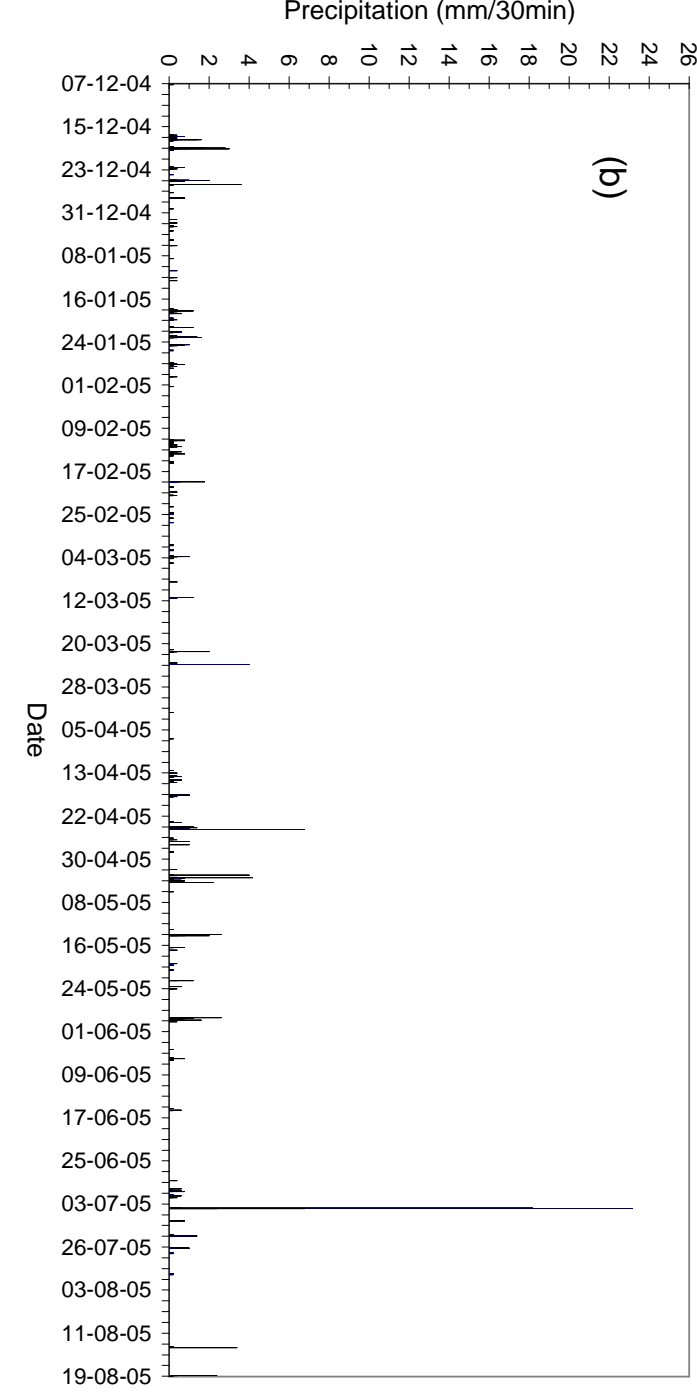

Solar radiation $\left(\mathrm{kW} / \mathrm{m}^{2}\right)$

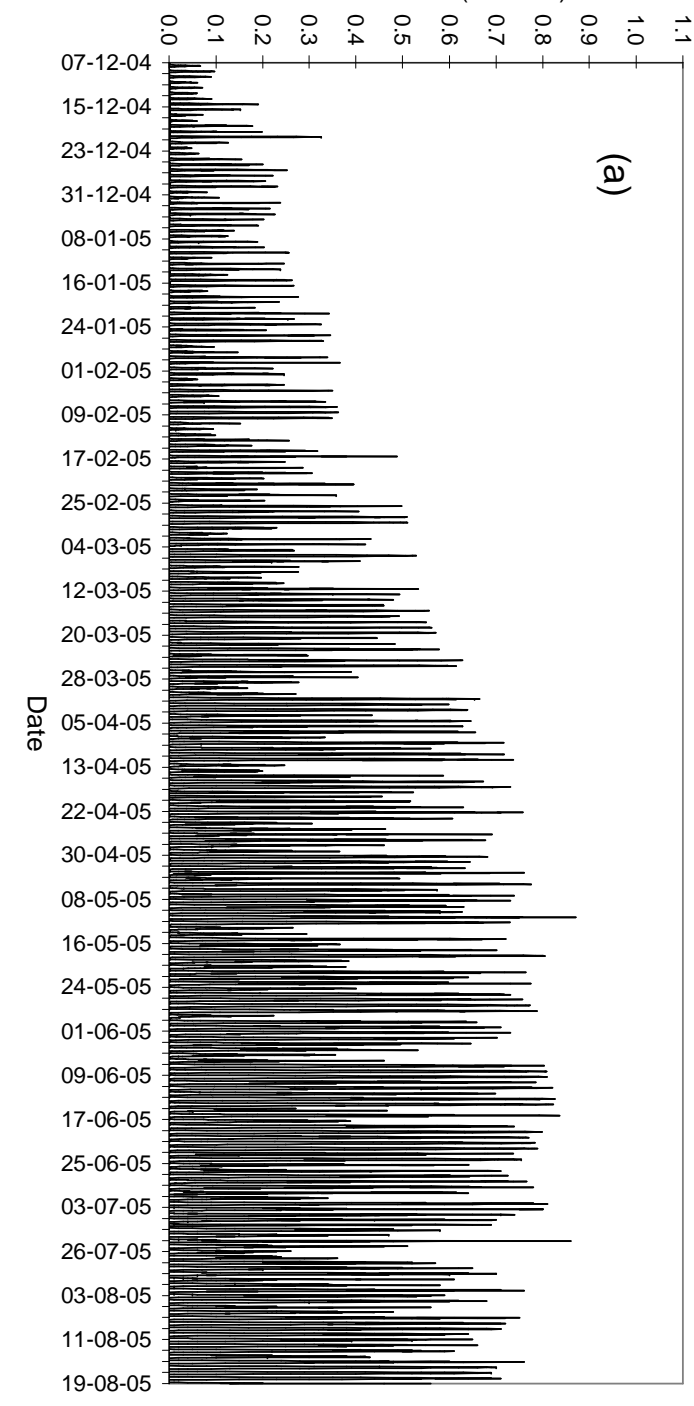



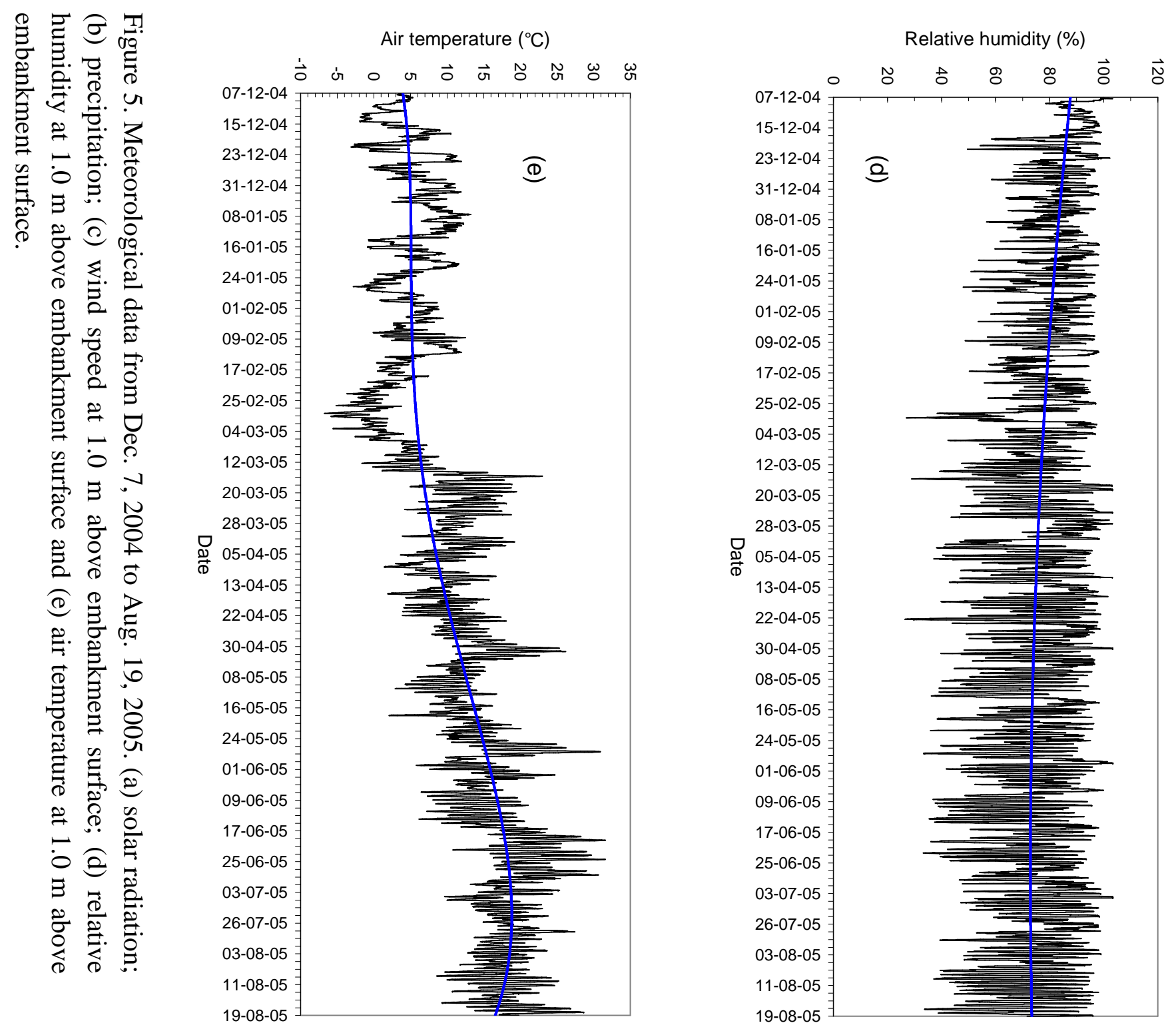
Volumetric water content (\%) N $N \underset{N}{N} N \quad N \quad W \quad W$

03/12/04

$13 / 12 / 04$

$23 / 12 / 04$

$02 / 01 / 05$

$12 / 01 / 05$

$22 / 01 / 05$

$01 / 02 / 05$

$11 / 02 / 05$

$21 / 02 / 05$

03/03/05

$13 / 03 / 05$

$23 / 03 / 05$

$02 / 04 / 05$

$012 / 04 / 05$

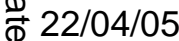

02/05/05

$12 / 05 / 05$

$22 / 05 / 05$

$01 / 06 / 05$

$11 / 06 / 05$

$21 / 06 / 05$

01/07/05

$11 / 07 / 05$

$21 / 07 / 05$

$31 / 07 / 05$

$10 / 08 / 05$

$20 / 08 / 05$

$30 / 08 / 05$

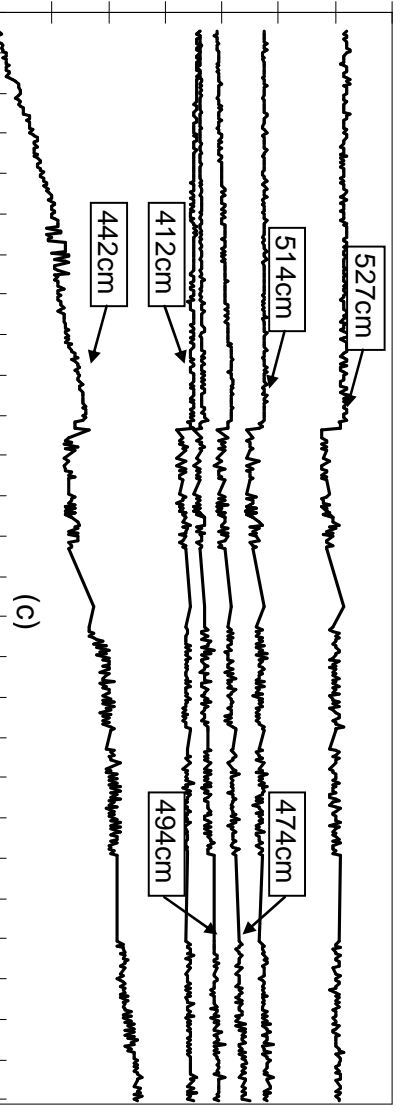

Volumetric water content (\%)

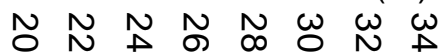

03/12/04

\section{$13 / 12 / 04$}

23/12/04

$02 / 01 / 05$

$12 / 01 / 05$

$22 / 01 / 05$

$01 / 02 / 05$

$11 / 02 / 05$

$21 / 02 / 05$

$03 / 03 / 05$

$13 / 03 / 05$

$23 / 03 / 05$

$02 / 04 / 05$

$\square 12 / 04 / 05$

22/04/05

02/05/05

$12 / 05 / 05$

$22 / 05 / 05$

$01 / 06 / 05$

$11 / 06 / 05$

$21 / 06 / 05$

$01 / 07 / 05$

$11 / 07 / 05$

$21 / 07 / 05$

$31 / 07 / 05$

$10 / 08 / 05$

$20 / 08 / 05$

$30 / 08 / 05$

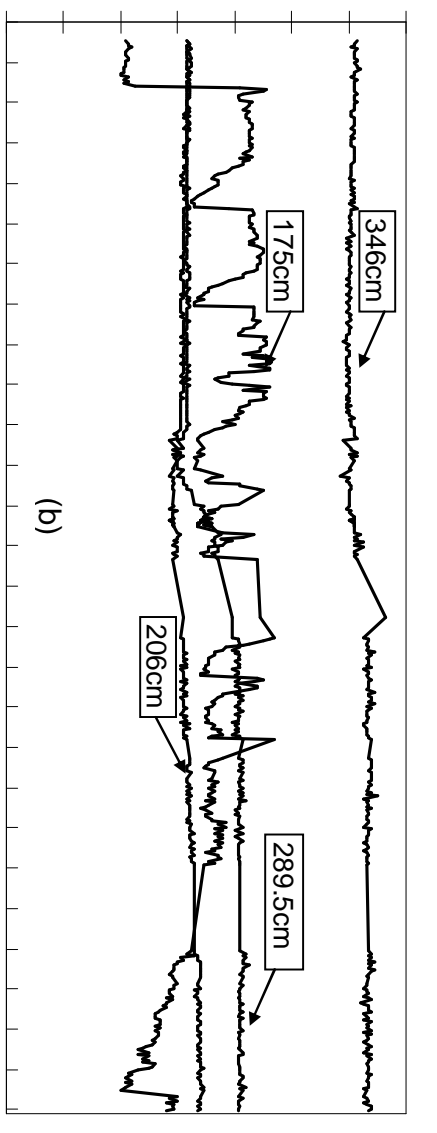

Volumetric water content (\%) $\sim N \sim N N N_{N}^{\omega} \omega$

03/12/04

$13 / 12 / 04$

$23 / 12 / 04$

$02 / 01 / 05$

$12 / 01 / 05$

$22 / 01 / 05$

$01 / 02 / 05$

$11 / 02 / 05$

$21 / 02 / 05$

$03 / 03 / 05$

$13 / 03 / 05$

$23 / 03 / 05$

02/04/05

ㅁ12/04/05

$\stackrel{\$}{\$} 22 / 04 / 05$

02/05/05

$12 / 05 / 05$

$22 / 05 / 05$

01/06/05

$11 / 06 / 05$

$21 / 06 / 05$

$01 / 07 / 05$

$11 / 07 / 05$

$21 / 07 / 05$

$31 / 07 / 05$

$10 / 08 / 05$

$20 / 08 / 05$

$30 / 08 / 05$

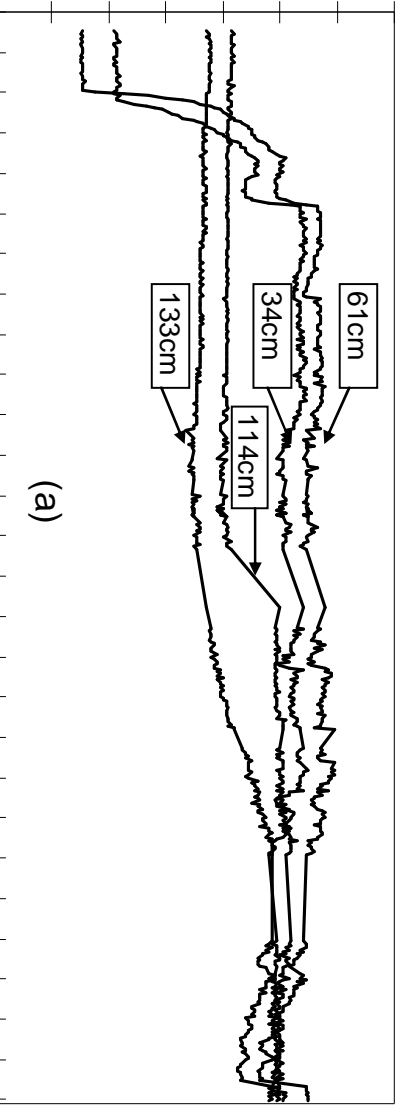


Pore pressure $(\mathrm{kPa})$

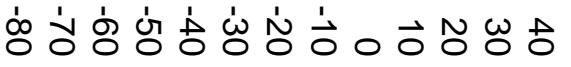

$03 / 12 / 04$

$13 / 12 / 04$

23/12/04

$02 / 01 / 05$

$12 / 01 / 05$

22/01/05

$01 / 02 / 05$

$11 / 02 / 05$

21/02/05

$03 / 03 / 05$

$13 / 03 / 05$

23/03/05

$02 / 04 / 05$

$\nabla_{12 / 04 / 05}$

$\stackrel{\oplus}{222 / 04 / 05}$

$02 / 05 / 05$

$12 / 05 / 05$

22/05/05

01/06/05

$11 / 06 / 05$

$21 / 06 / 05$

01/07/05

$11 / 07 / 05$

$21 / 07 / 05$

$31 / 07 / 05$

$10 / 08 / 05$

$20 / 08 / 05$

$30 / 08 / 05$

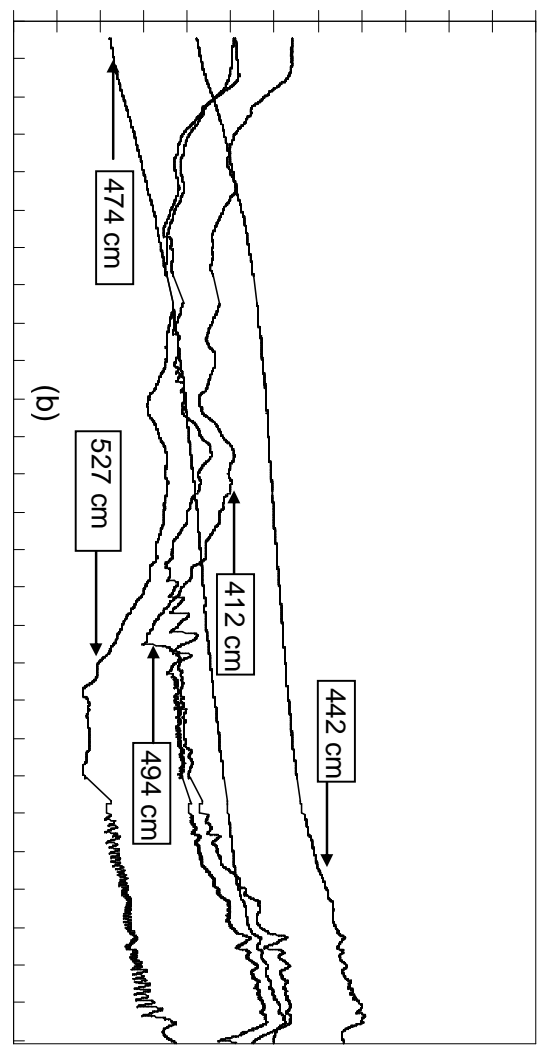

:

હ)
Pore pressure (kPa)

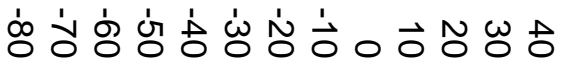

$03 / 12 / 04$

$13 / 12 / 04$

23/12/04

$02 / 01 / 05$

$12 / 01 / 05$

$22 / 01 / 05$

$01 / 02 / 05$

$11 / 02 / 05$

21/02/05

03/03/05

$13 / 03 / 05$

23/03/05

02/04/05

$\nabla_{12 / 04 / 05}$

क्ञ22/04/05

02/05/05

$12 / 05 / 05$

22/05/05

$01 / 06 / 05$

$11 / 06 / 05$

$21 / 06 / 05$

01/07/05

$11 / 07 / 05$

$21 / 07 / 05$

$31 / 07 / 05$

10/08/05

20/08/05

$30 / 08 / 05$

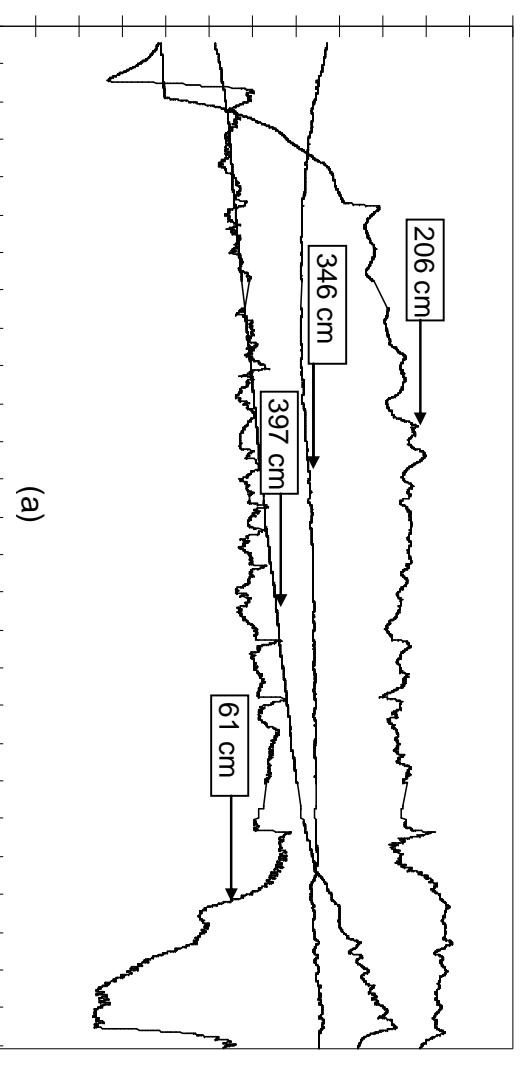




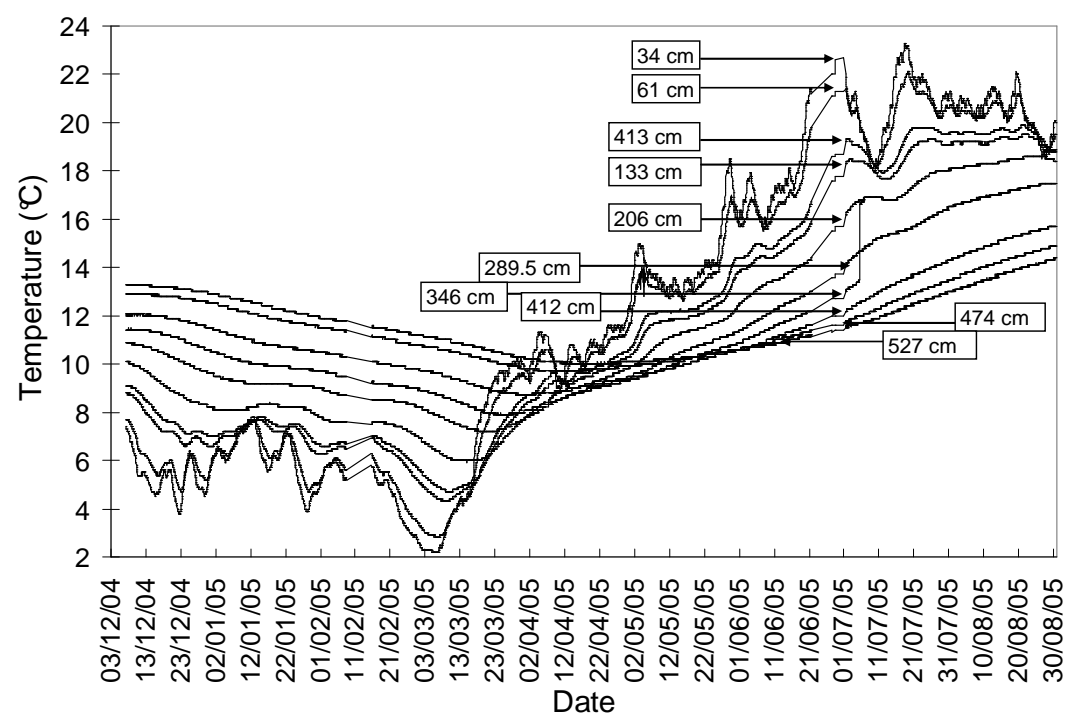

Figure 8. Variations of soil temperature at various depths on the central axis.
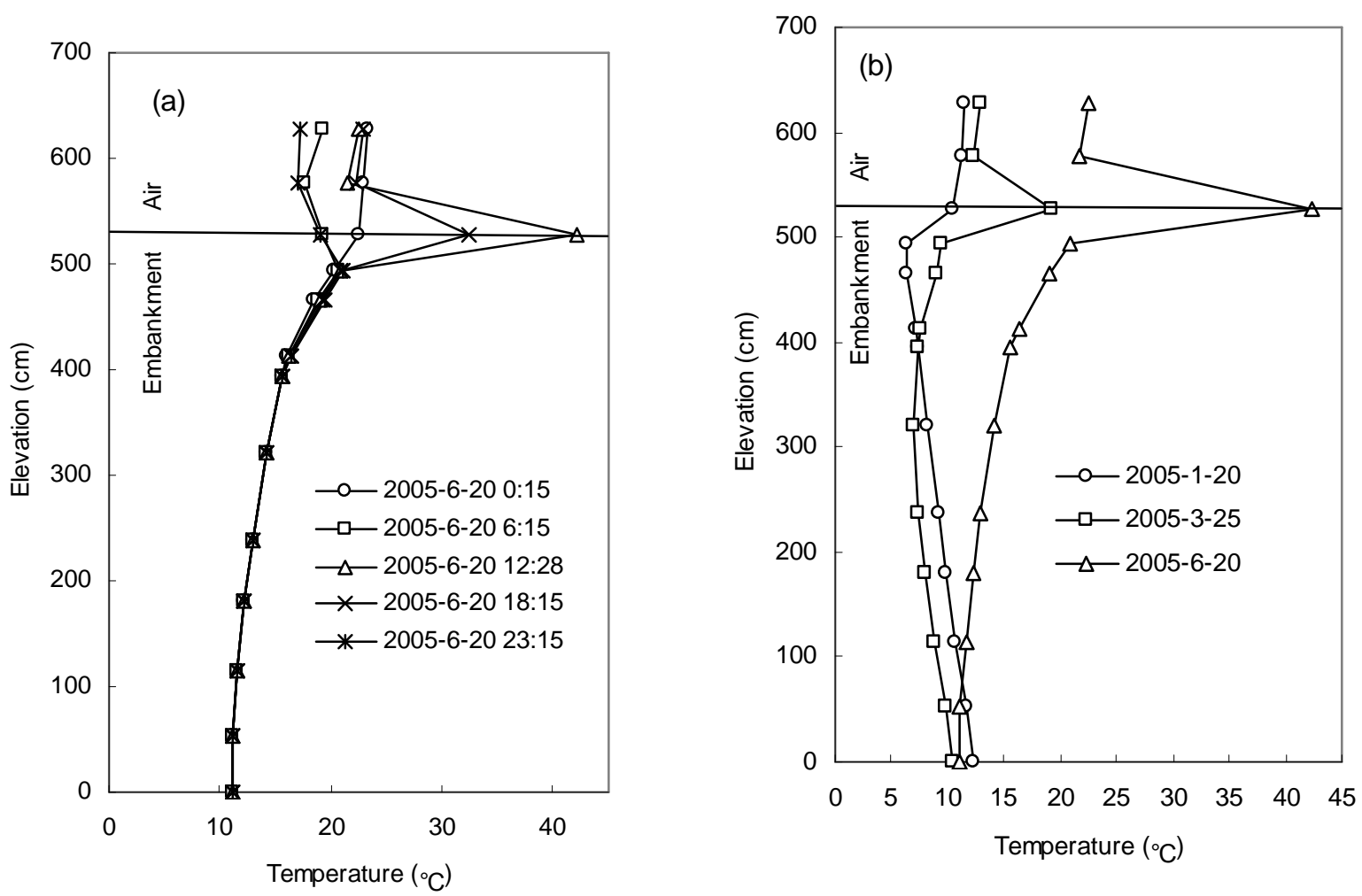

Figure 9. Measured temperature profiles on the central axis. (a) changes during 24 hours and (b) changes during 5 months. 


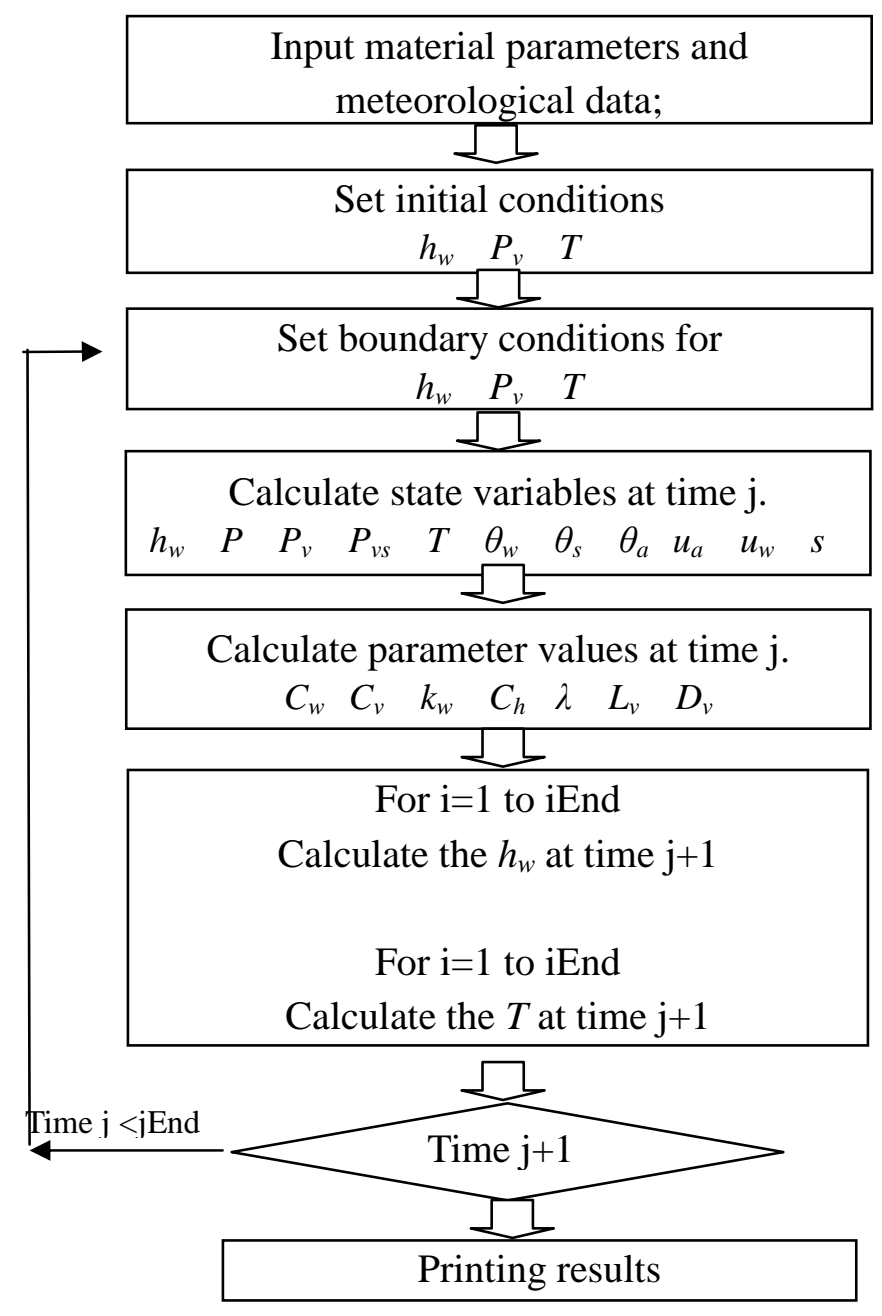

Figure 10. Calculation scheme. 

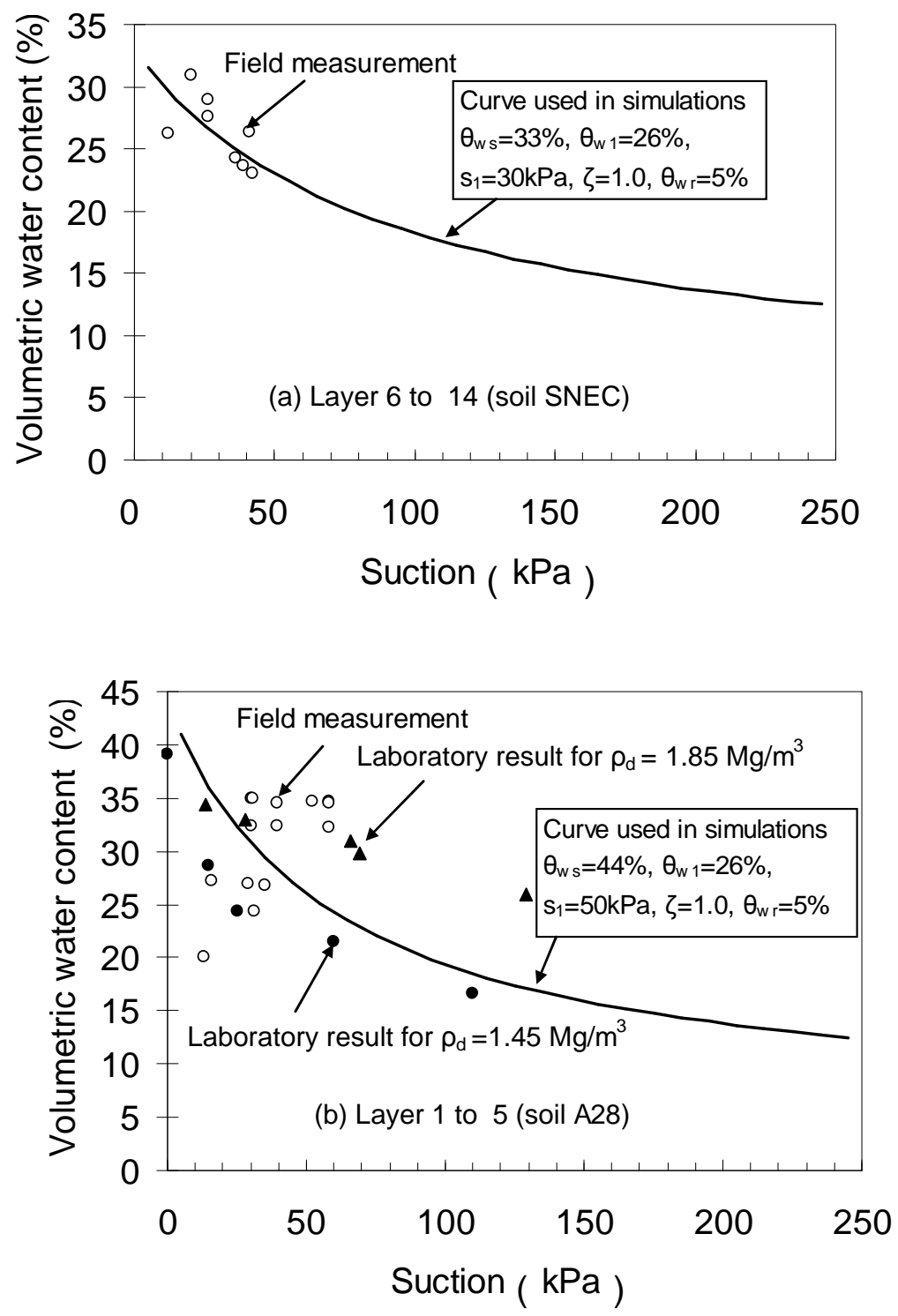

Figure 11. Water retention curve determination based on the field data. (a) layer 6 to 14 for soil SNEC and (b) layer 1 to 5 for soil A28.

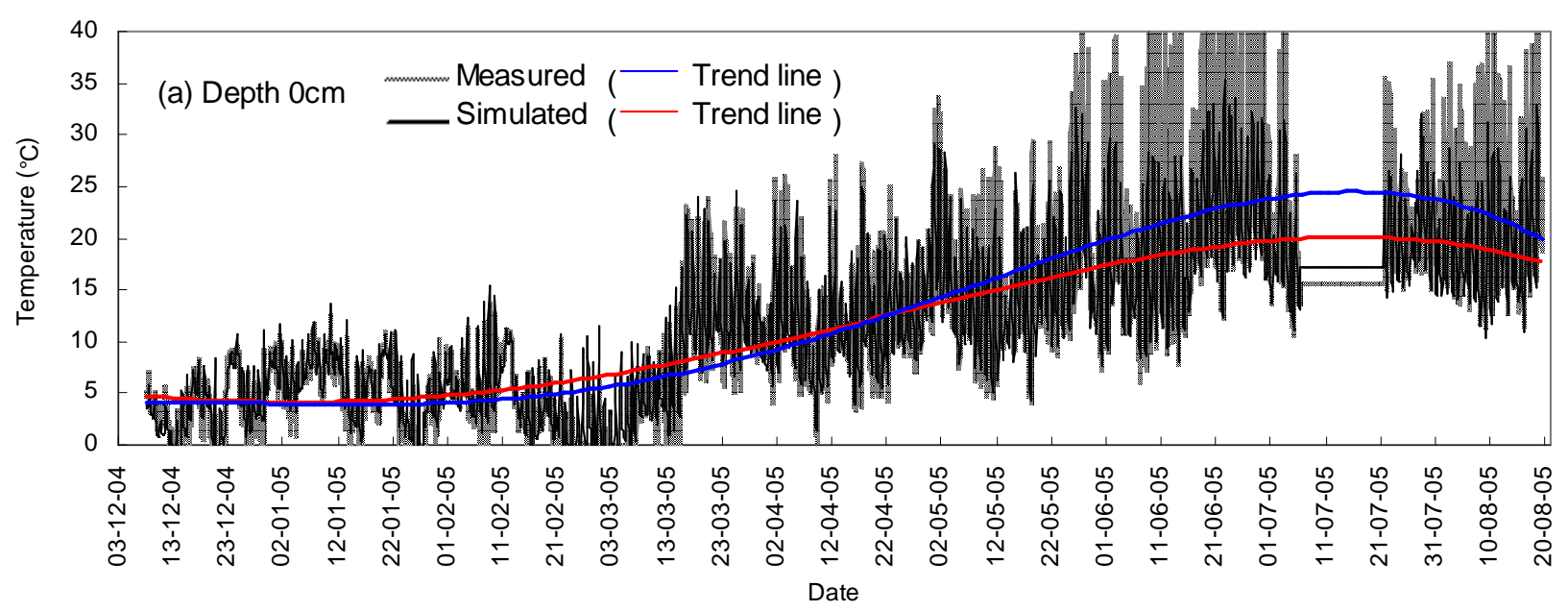

Figure 12. Temperature variations at the soil surface. 

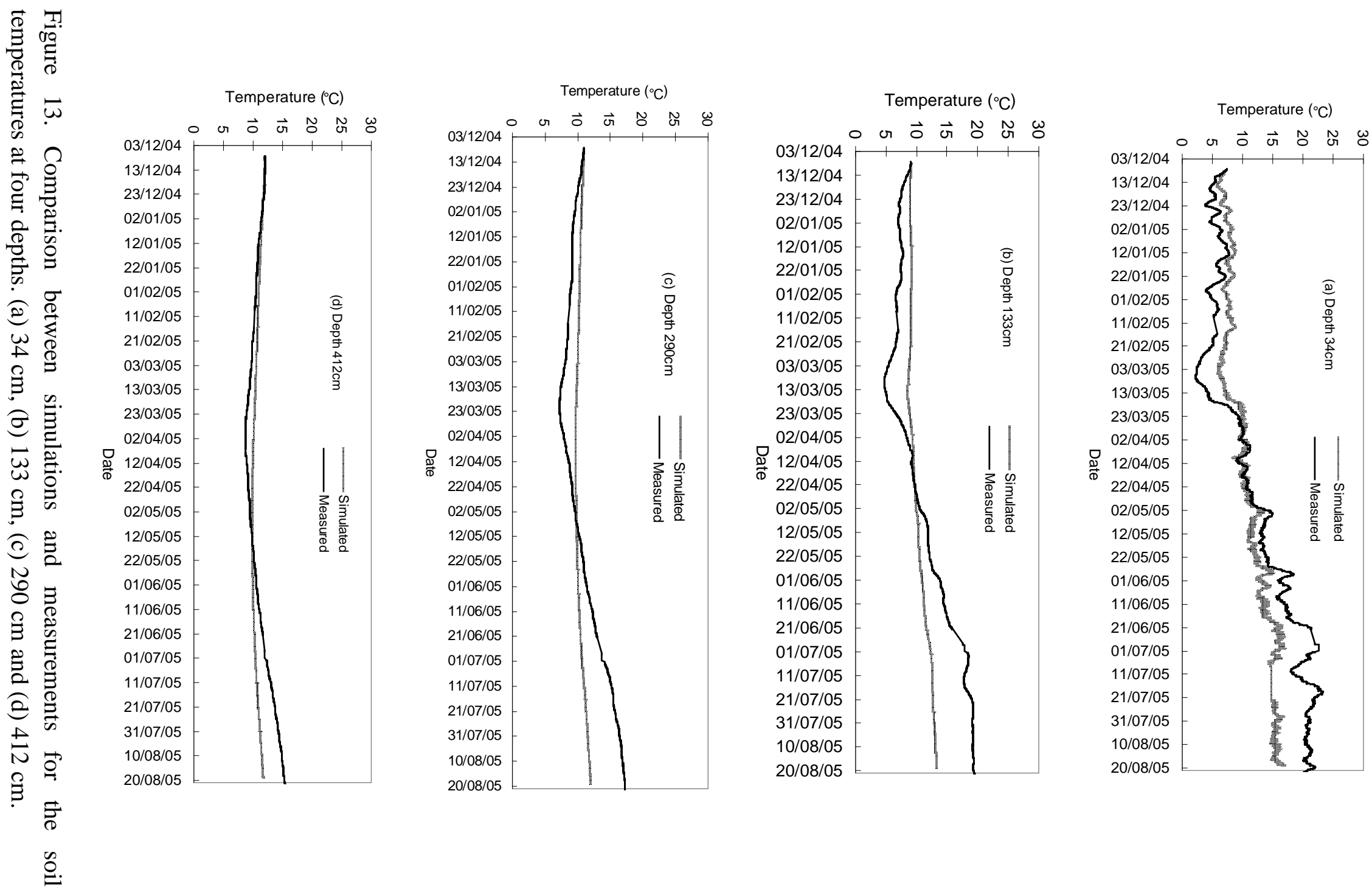
Suction (kPa)

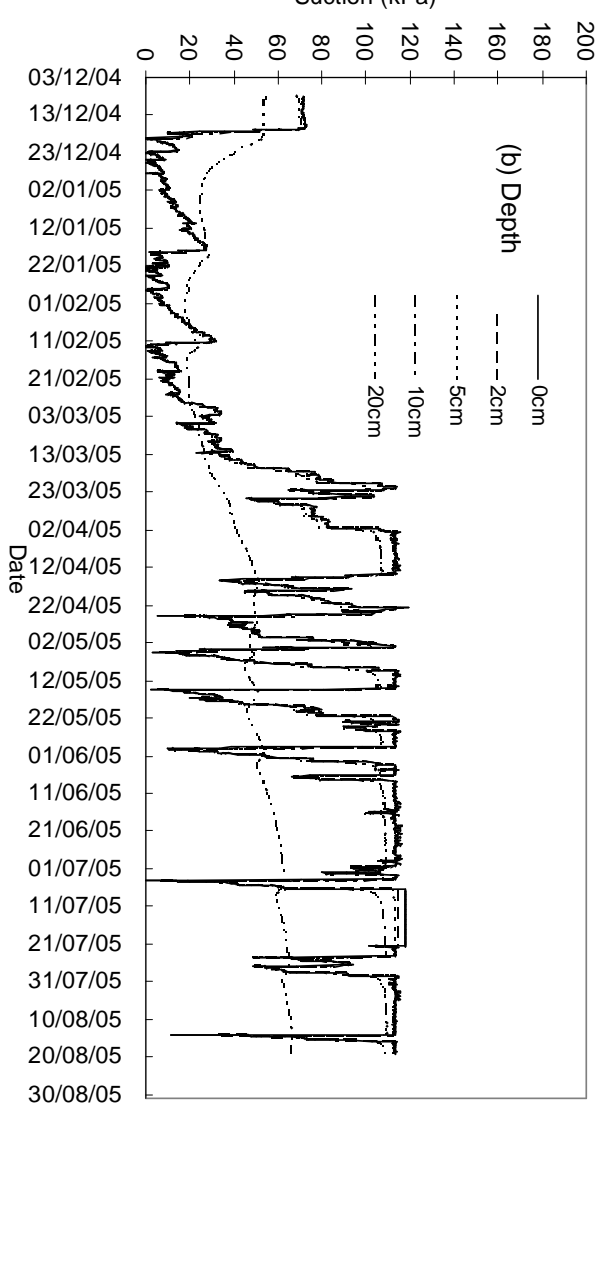

雨

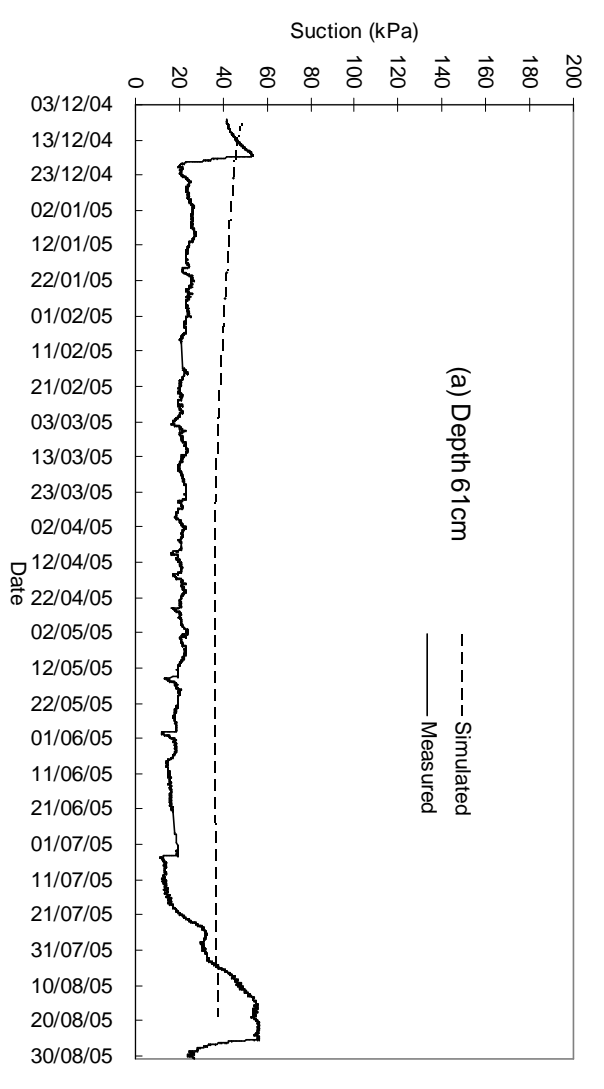

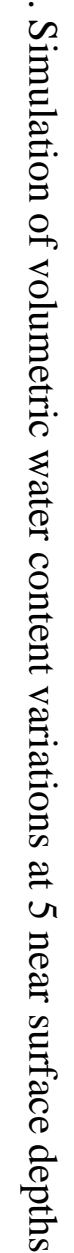

Volumetric water content (\%) - $r$ o $\vec{\sim}$ N N 03-12-04 13-12-04 23-12-04

02-01-05

12-01-05

22-01-05

01-02-05

11-02-05

21-02-05

03-03-05 i.. 대웡

13-03-05

23-03-05

02-04-05

12-04-05

बै 22-04-05

02-05-05

12-05-05

22-05-05

01-06-05

$11-06-05$

21-06-05

01-07-05

11-07-05

21-07-05

31-07-05

10-08-05

20-08-05

30-08-05

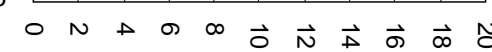

Precipitation (mm/30min) 